\title{
HISTORIA POLÍTICA DE LA FILOSOFÍA DEL DERECHO ESPAÑOLA DEL SIGLO XX *
}

\author{
Benjamín Rivaya \\ Universidad de Oviedo
}

RESUMEN. Ésta es una historia de la Filosofía del Derecho española de entre las varias posibles, que se caracteriza por vincular el desarrollo de la filosofía jurídica al desarrollo político del país, por señalar quiénes fueron - a juicio del autor- los motores de la especulación iusfilosófica durante el pasado siglo y por plantear y tratar de dar respuesta a los enigmas de esta historia.

Palabras clave: Historia de la Filosofía del Derecho, Filosofía del Derecho española, Filosofía del Derecho contemporánea.

ABSTRACT. This one is a history of the Spanish philosophy of Law among several possible others. It is characterized for linking the development of legal philosophy to the political development of the country, for indicating those who were -in the opinion of the author- the engines of the philosophy of Law during the last century, and for considering and trying to unravel the cruxes of this history.

Keywords: History of Philosophy of Law, Spanish Philosophy of Law, Contemporary Philosophy of Law.

* Fecha de recepción: 28 de septiembre de 2009. Fecha de aceptación: 29 de octubre de 2009.

Una versión ampliada de este trabajo en B. RIVAYA, Una bistoria de la Filosofía del Derecho española del siglo XX, Madrid, Iustel, 2010. 


\section{LAS TRES PRIMERAS DÉCADAS DEL SIGLO XX: MONOPOLIO ACADÉMICO NEOTOMISTA Y ALTERNATIVAS MODERNISTAS (1901-1931)}

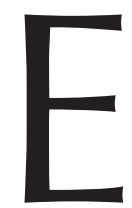

n España, a la altura de 1900, las cátedras de Elementos de Derecho Natural, nombre de la asignatura iusfilosófica de la licenciatura en aquel tiempo, están ocupadas por escolásticos de más que menos estricta observancia (GIL CREMADES, 1969, p. 190). Oviedo y Madrid son las excepciones; por poco tiempo. En la Universidad asturiana nos encontramos con un krausista, L. ALAS, pero fallecerá al año siguiente, en 1901, siendo en breve sustituido por un católico atronador, F. PÉrez Bueno. En Madrid, en la cátedra de doctorado de Filosofía del Derecho se encuentra precisamente el maestro filosófico del literato (y de otros muchos), F. GINER DE LOS RíOS, pero cuya obra fundamental ya está escrita en el diecinueve. Morirá en 1915. Evidentemente, no es que ya no hubiera krausistas; es que, muy avanzado el XIX y a principios del XX, habían fracasado en su intento por hacerse con las cátedras de Derecho natural, aunque a cambio ocuparon otras. En cualquier caso, el iusnaturalismo krausista había removido las aguas de la Filosofía del Derecho. Importa advertir, para no caer en simplificaciones, que si bien se hallaba distante del otro iusnaturalismo, del escolástico, esa distancia no impedía que compartiera fundamentales ideas con él: «es indudable que la escuela teológica, así en el reconocimiento del derecho divino como en el fundamento ético que da a la ciencia jurídica — decía AlAs—, se acerca mucho a lo que tenemos por verdadera doctrina» (Alas, 1878, p. 141). Probablemente lo que más les distanciaba era el «carácter eminentemente liberal» de esta doctrina verdadera (DíAZ, 1973, p. 59; también PÉREZ LuÑo, 2007, p. 131), frente a una tendencia mucho más conservadora de la otra doctrina también verdadera (RUBIO CASTRO, 1984, p. 133). Pero el krausismo filosófico jurídico ya era siglo XIX, es decir, pasado, y si a ello unimos que el historicismo, sobre todo catalán, no tendría recambio, ni continuadores el hegelismo, y que el positivismo no había logrado arraigo en nuestro suelo, se puede comprender el monopolio que en la filosofía profesional del Derecho van a ejercer los escolásticos durante los comienzos de la nueva centuria. Salvo las excepciones vistas de Alas y de GiNER, los catedráticos que cruzaron el siglo y vivieron algo del nuevo eran neotomistas, y también los que accedieron a la cátedras ya en los comienzos de la nueva centuria.

De ese Derecho natural de principios de siglo no ha quedado muy buen recuerdo, sobre todo - me parece- debido a la opinión de RECASÉns, que lanzó un juicio durísimo contra casi todos los representantes del iusnaturalismo católico de entresiglos (en concreto citaba al padre José Mendive S. I., al padre Ceferino González O. P., a Juan Manuel Ortí y Lara, al padre Juan Urraburu S. I., a Pedro López Sánchez, a Francisco Javier González de Castejón y Elio, marqués de Vadillo, y a Rafael Rodríguez de Cepeda) que «no ofrecen apenas interés — dijo—: no muestran ni extensos ni profundos conocimientos de los grandes autores clásicos de la escolástica; se limitan a repetir fórmulas inertes y definiciones recibidas de segunda o tercera mano; y padecen el frenesí de combatir todo cuanto sea pensamiento moderno ajeno sobre el que vierten los más violentos denuestos, calificándolo de "locuras", "absurdos", "monstruosidades", etc.». Y continuaba: «Muchos se inspiran en fuentes de tan ínfima calidad intelectual como 
el del italiano Prisco, en tanto que desconocen los textos de Santo Tomás, de Suárez, de Soto y de las demás figuras cumbres de la escolástica» (RECASÉNS, 1936, pp. 450451). Aunque quizás hubiera que matizar juicio tan duro (¿también es razonable en el caso del cardenal Zeferino González?), es cierto que ha generado consenso: el iusnaturalismo español de finales del XIX y principios del XX no presentaría singularidad alguna, dedicado a reproducir lo ya dicho anteriormente, sobre todo en línea con el neotomismo italiano. Sólo L. MeNDIZÁBAL será salvado de la quema (RECASÉNS, 1936, p. 451). Desde luego, MENDIZÁBAL era un fiel tomista pero, por una parte, parecía que no era un vulgarizador y, por otra, estaba más abierto que otros a la novedad, como demuestra la última edición de su Tratado (1928), reelaborado por él con la ayuda de su hijo Alfredo. Su interés aumenta si tenemos en cuenta que dio origen a la llamada Escuela Aragonesa de Derecho natural, de la que formaron parte M. SANCHO IzQUIERDo, A. Mendizábal Villalba, E. Luño Peña, L. Legaz LaCambra y R. Pérez Blesa, todos ellos protagonistas de esta historia.

El monopolio neoescolástico se mantendrá durante largo tiempo. Algunos de los viejos iusnaturalistas desaparecen: R. RODRÍGUEZ DE CEPEDA fallece en 1918 y F. J. GONZÁlEZ CASTEJÓN ELIO al año siguiente, en 1919. Llegan otros nuevos: M. SANCHO IZQUiERDO y M. Puigdollers logran la cátedra en 1920; W. GonZÁlez Oliveros, en 1922. No se atisban modificaciones en el pensamiento jurídico y político escolástico. Aunque habría que apuntar matices, en general sus seguidores mantenían una ideología conservadora, más moderada a veces, más radical en ocasiones. No creo errado decir, por tanto, que en aquel tiempo la filosofía del Derecho académico era claramente conservadora. En cierta medida, la historia de ésta es, por una parte, el intento de esa filosofía que bien podríamos denominar católica de mantener el predominio ideológico y, a la vez, la resolución de otros, no siempre subversivos ni antiteos, de quebrar el monopolio. Aunque también es cierto que hubo escolásticos que trataron de que el pensamiento tomista no se petrificara, adaptándolo al mundo moderno, caso de A. MEndizÁBAL. Así, los nuevos catedráticos seguían la misma dirección filosófica, la mayoritaria en España. Durante todo este tiempo sólo uno, que yo sepa, B. RAmos SOBRINO, podría haber jugado un papel transformador, pero no lo hizo.

B. RAmos pertenecía a la escuela de L. Díez CANSECo, escuela que, además de no poseer una ideología común, se caracterizó por su resistencia a la escritura: todos sus miembros fueron ágrafos o casi ágrafos; tanto el maestro como los que parece que fueron sus discípulos, E. CAllejo DE la Cuesta y B. Ramos Sobrino. En cuanto a Díez CANSECO, obtuvo cátedra de Derecho natural en Valladolid, en 1900, y luego la dejó a cambio de otra de Historia del Derecho en Madrid. De E. Callejo poco se puede decir, salvo que se adhería al neotomismo y que su escasa obra científica carece de interés. Por fin B. Ramos, que obtuvo la cátedra en 1918, quizás hubiera podido ser un transformador, desde dentro, de la Filosofía del Derecho española, pero ya está dicho que no fue así. Se trataba de un filósofo peculiar, creo que confuso, en el que se daban cita desde STAMMLER, pasando por DeWEy, hasta PASCHUKANIS, pero no publicó nada en vida. Lo que importa en cualquier caso es que, al margen de la excepción, se puede observar que en las primeras décadas del siglo Xx el acceso a las cátedras siguió beneficiando a los escolásticos, que así continuaron monopolizando la academia filosófico-jurídica. El dato es sin duda negativo: el pluralismo va en beneficio no sólo 
del pensamiento en general sino de sus concretas tendencias, que así tienen que revisar sus argumentos e idear otros para hacer frente a quienes no comulgan con sus tesis.

Lo expuesto no significa que durante las primeras décadas del siglo XX no hubiera alternativas iusfilosóficas al escolasticismo reinante, pero tuvieron que surgir fuera del ámbito académico de la filosofía jurídica, controlado, como vemos, por la misma dirección. Habría que citar, por una parte, las ideologías jurídico-políticas del movimiento obrero. El socialismo de tendencia marxista y, sobre todo, el anarquismo estaban establecidos en España desde el XIX, y tenían sus propias concepciones del Derecho. De mayor implantación gozaban los ácratas, pero entre los marxistas va a destacar un asturiano que tendrá enorme importancia en esta historia, W. ROCES. Por otra parte, ya no ideólogos del obrerismo sino juristas académicos, casi siempre profesores universitarios pero de otras ramas, contribuyeron a la elaboración de tesis que se enfrentaban también con la escolástica dominante en la Filosofía del Derecho. Es el caso, por ejemplo, de D. MONTERO, penalista, personalidad singular y positivista en su Filosofía del Derecho, en el sentido de que aplicaba el método positivo al estudio del fenómeno jurídico y repudiaba el Derecho natural. Habría que citar también a otro penalista, Q. SALDAÑA, partidario de una teoría pragmática del Derecho, interesada no en la teoría sino en la práctica jurídica, no en la validez sino en la eficacia del Derecho. Fuera del ámbito académico llama la atención L. HERNÁNDEZ RICO y su concepción belicista del Derecho. Pero también hay que hacer referencia a los dos grandes pensadores de la España de principios de siglo. Por una parte a UnAmunO, que ya había comenzado a escribir en el XIX, pero cuya obra fundamental será del XX. Por otra parte a ORTEGA, cuyos escritos arrancan en 1902. ¿Tenían ambos genios alguna Filosofía del Derecho?

En cuanto a UNAMUNO se suele ver su ideología jurídica en el capítulo XII de la primera parte de la Vida de don Quijote y Sancho, en el que comenta la «liberación de los galeotes». En principio puede sintetizarse la postura de UNAMUNO con sus propias palabras: «no hay castigo humano que sea absolutamente justo». Pero realmente va más allá, mucho más allá. Lo natural y divino al mismo tiempo es, movida por la cólera del momento, la venganza, pero tras ésta surge el perdón. «Castigo que no va seguido de perdón, ni se endereza a otorgarlo al cabo — dice-, no es castigo, sino odioso ensañamiento». Por eso el Código Penal es inhumano y por eso mismo, también, es intolerable que la llamada justicia se administre en nombre de Dios. Quien cree en Dios y en la salvación, «en que al cabo todos hemos de ser perdonados», no tiene el deber de hacer justicia, de retribuir el mal con el mal, sino de perdonar. «Ya os veo aquí, lectores timoratos, llevaros las manos a la cabeza y os oigo exclamar: ¡qué atrocidades! Y luego habláis de orden social y de seguridad y de otras monsergas por el estilo» (1988, pp. 250-258). ¿Cómo no recordar al príncipe Nejliúdov, el protagonista de Resurrección, de Tolstoi? En efecto, UnAMUNO ve las cosas jurídicas como las vio TOLSTOI, poco más o menos, con la lente de la exaltación religiosa, de un cristianismo evangélico radical que se dedicaba a resaltar el carácter pecaminoso del Derecho.

En cuanto a J. ORTEGA y GASSET, que estaba llamado a convertirse en el filósofo español del siglo XX, también juega un papel fundamental en la historia de la Filosofía del Derecho de acá. En su primera obra, las Meditaciones del Quijote, dejará apuntadas gran cantidad de sugerencias y cuestiones que serán fácilmente aplicables a la Filosofía del Derecho. Tantas sugerencias, muchas de ellas, hallarán explicación (aunque otra 
vez inacabada, fragmentaria, dispersa) en la próxima obra del filósofo, y a partir de la década de los treinta ejercerán un enorme influjo en la filosofía jurídica española, aunque el libro en el que expondría la que llamará su teoría sociológica (repárese en la expresión, porque incluye la jurídica), libro ya póstumo, aparecería mucho más tarde, en 1957, con el título de El hombre y la gente (1980), si bien es verdad que recopilaba ideas de mucho antes. En síntesis, ORTEGA seguía los pasos de DuRKHEIM en su entendimiento de la sociedad, que definía como una «ingente arquitectura usual». Porque la clave de la bóveda conceptual de la sociedad era el uso, la norma, el esquema de conducta que volvía inteligible el actuar humano. Frente a la vida auténtica, aquella en la que cada cual hace lo que desea, lo que quiere, lo que siente o piensa por sí, se alza otro tipo de existencia, la inauténtica, en la que los individuos se comportan como funcionarios del grupo, hacen lo que se hace, renunciando a cualquier originalidad. Eso son los usos: pautas impersonales, coactivas e irracionales, en tanto que tuvieron un sentido pero, precisamente cuando se convirtieron en usos, lo perdieron. ORTEGA clasifica los usos en débiles y fuertes, y el Derecho - así lo dice- es el uso fuerte por excelencia, el que llega a utilizar la coacción máxima, la física; incluso, en las sociedades desarrolladas, por medio de una organización dedicada expresamente a eso, el Estado. Hay que decir que OrTEga tenía en alta estima tanto los usos en general como el Derecho en particular, pues hacían posible una vida a la altura del tiempo. Semejante sociologismo, como digo, tendrá hondo influjo en la Filosofía del Derecho española, hasta el punto de que si se puede hablar de una filosofía jurídica española en el siglo XX, una filosofía no importada del extranjero, ésa será la de ORTEGA.

Pero ahora debemos volver los ojos otra vez hacia el krausismo, pues podremos observar interesantes movimientos iusfilosóficos. Porque si bien como filosofía jurídica académica ya sabemos que el krausismo había completado su ciclo, cumplido su misión, como movimiento modernizador, sin embargo, aún tendrá tiempo de impulsar la renovación de la ciencia española y, por lo que ahora más nos interesa, la de la Filosofía del Derecho. Lo digo porque fue la ideología de esos filósofos idealistas la que inspiró el proyecto de la Junta para la Ampliación de Estudios e Investigaciones Científicas, y si resulta difícil exagerar la importancia de ésta para todos los ámbitos del saber, lo mismo sucede en el caso de la especulación filosófico-jurídica. Repárese en el dato de que sobre todo hayan sido filósofos del Derecho, discípulos de E. DíAz, quienes han historiado la labor de la Junta. Aunque sea adelantar noticias, sépase también cuántos filósofos académicos del Derecho se beneficiaron entre 1907 y 1936 de las becas de la Junta, con las que pudieron irse al extranjero, sobre todo a Alemania, a estudiar junto a los pensadores más punteros de la especialidad: por lo menos, F. RIVERA PASTOR, B. Ramos Sobrino, L. Recaséns Siches, E. Luño Peña, L. Legaz Lacambra, J. Corts GRAU o F. GONZÁLEZ ViCÉN. El efecto primero fue un aumento de las traducciones, en este caso de obras filosófico jurídicas. Como se comprenderá fácilmente, la historia de la traducción es una parte fundamental de la historia de la filosofía del Derecho española (vid. Gil CREMADES, 2004, pp. 17-60). El monopolio de la Filosofía profesional del Derecho española era de la neoescolástica, pero ahora se abrieron las puertas al neokantismo. A J. CASTILLEJO, que fue el alma de la Junta, se debe el inicio de un interesante capítulo de la Filosofía del Derecho española, el de la recepción del neocriticismo de STAMMLER en nuestra patria. CASTILLEJO fue becado en 1903 por el Ministerio de Instrucción Pública, a propuesta de la Universidad de Oviedo, para irse a 
estudiar a Berlín, donde siguió las explicaciones de Derecho comparado de J. KOHLER. Luego, en la Universidad de Halle conoció personalmente a R. STAMMLER y quedó impresionado con sus clases. Cuando luego pueda influir en la elección del destino de los jóvenes becarios de la Junta, no extrañará que muchos de quienes provenían del campo del Derecho acabaran estudiando con el neokantiano, cuyas obras fundamentales serán traducidas por becarios que estudiaron con él: F. RIVERA PASTOR, W. ROCES y L. RECASÉNS.

«Stammler en España» es un capítulo fundamental de la historia iusfilosófica española y, además, la expresión se puede tomar en un sentido literal, pues estuvo aquí, en la Universidad Central y en la de Granada. En la capital ofreció al público madrileño varias conferencias que luego se publicaron bajo el título de «Cuestiones fundamentales de Filosofía del Derecho», traducidas y prologadas por F. RIVERA PASTOR (STAMMLER, 1922). A su vez, las conferencias que ofreció en Granada, en la primavera de 1922, fueron traducidas por RoCES, en un librito que se tituló La génesis del Derecho, recientemente reeditado (2006). Los citados traductores, además, publicaron obras típicamente neokantianas: de RIVERA PASTOR es Lógica de la libertad (1918), libro en el que seguía la senda del maestro y en el que posó sus ojos nada menos que OrTEGA, que ya entonces consideraba superado a STAMMLER (1994). De RoCES son varios artículos en los que, aunque advirtiera que la obra de STAMMLER debía ser criticada, seguía fielmente los pasos del maestro, al menos en lo tocante al concepto del Derecho (1924, 1925). A RocEs se debe, por lo demás, la traducción del Tratado de Filosofía del Derecho (1930) y Economía y Derecho (1929), además de La génesis del Derecho (1925), ya citada, y quizás otro libro titulado Teoría del Derecho justo, aunque nunca he llegado a encontrarlo. Por fin, a RECASÉNS también se le notará la ascendencia stammleriana, por mucho que lo considerase superado, y parece que él realizó la traducción, en 1930, de su Introducción a la ciencia del Derecho (según información de GIL CREMADES, 1987, pp. 565-566), con lo que se puede decir que todos los escritos fundamentales del maestro neokantiano se trasladaron al español. Pero por mucho que adeudara el presente iusfilosófico de entonces a STAMMLER, su especulación, rígidamente formalista, ya era cosa del pasado. El certificado de defunción no de STAMMLER sino de su doctrina lo extendió LEGAZ en 1936, precisamente con motivo de la celebración del octogésimo aniversario de aquél (1947).

También desde principios del siglo Xx se dio a conocer en España, sobre todo por medio de traducciones y más adelante de estudios, a G. DEL VECCHIO, otro neokantiano que también se alzaría contra el positivismo, si bien su filosofía jurídica era -me parece- menos formalista que la de STAMMLER. El primer libro del italiano que se vertió al español (por el notario M. CASTAÑO) fue Los supuestos filosóficos de la noción de Derecho, ya en 1908, y desde entonces no dejarían de aparecer traducciones hasta el momento de su fallecimiento, que se produciría en 1970; y aún después seguirían reeditándose sus obras. Si STAMmLER había sido el filósofo del Derecho con el que más españoles habían estudiado, DEL VECCHIO va a ser —creo- el más traducido del siglo XX (honor que quizás comparta con otro iusfilósofo italiano, N. BOBBIO). En abril de 1923, por tanto poco antes de que PRIMO DE RIVERA tome el poder, G. DEL VECCHIO visita España invitado por la Universidad Central de Madrid y por la de Granada, en las que pronunciará varias conferencias que luego se publicarán, en el caso 
de las de la Central, traducidas por F. PéRez Bueno. Del VeCCHIO era un filósofo del Derecho respetado, pero para ese entonces ya pertenecía al Partido Fascista y había acompañado a Mussolini en su marcha sobre Roma. Probablemente fue en este viaje cuando aprovechó para fundar el Fascio italiano en Madrid, pues lo hizo precisamente en 1923.

En cuanto a la cultura jurídica francesa, otrora tan influyente, siguió siendo recibida por medio de traducciones y estudios, aunque éstos no solieran ser de filósofos profesionales del Derecho. A principios de siglo apareció el mejor ejemplo del país vecino de la revuelta contra el formalismo, el de F. GENY, con su Método de interpretación y fuentes en Derecho privado (1902). Más adelante se incorporarían a la lengua castellana tanto Duguit como Hariou.

\subsection{La Filosofía del Derecho durante la dictadura de Primo de Rivera y la crisis de la Monarquía (1923-1931)}

Si nos fijamos en el escalafón de la asignatura, ya sabemos que alrededor de 1920 obtienen cátedra algunos iusfilósofos que, por una u otra razón, no siempre por su actividad intelectual, serán significados: M. SANCHO IZQUiERDO, M. PUigdOLLERS Oliver, W. GonZÁlez Oliveros. Si a ello añadimos que en 1904 la había obtenido el ya citado F. PÉrez Bueno, en la Universidad de Oviedo, y que en 1912 la consiguió E. CALLEJO DE LA CUESTA, parece que hay algún tipo de relación entre la Filosofía del Derecho y los cuadros de la dictadura: Pérez BUENO se vanagloriaba de ser ideólogo de la dictadura (1925, p. 52); SANCHO IZQUIERDO colaboró, aunque fuera en un organismo técnico (GIL CremAdes, 1989, p. 445); W. GonZÁLEZ OlIVEROS fue director general de Enseñanza Superior en el Ministerio de Callejo; y CALLEjo, por fin, además de participar en la creación de la primorriverista Unión Patriótica, fue ministro de Instrucción Pública en el Directorio Civil (1925-1930), con lo que no ha pasado a la historia como filósofo del Derecho sino como ministro, que por cierto modificó el plan de estudios de la licenciatura de Derecho, estableciendo la asignatura de Derecho natural en primer curso y la de Filosofía del Derecho en el último año de la carrera. Si nos fijamos en la Asamblea Consultiva creada por Primo para legitimarse volveremos a ver a varios de esos filósofos y a algunos otros (HERNANDO SERRA, 2004, pp. 231-257). Como representación de la Filosofía del Derecho, no está mal.

Sin embargo hay que afirmar que si bien en el comienzo Primo de Rivera obtuvo la aquiescencia de algunos intelectuales, con el tiempo perdió la de casi todos. Desde el inicio nada menos que el genio iconoclasta de UNAMUNO se había puesto enfrente, representando la oposición contra la dictadura. Su ayudante en este empeño lo fue un jurista ya citado, W. ROCES, catedrático de Romano en la Universidad de Salamanca pero orientado a la Filosofía del Derecho, hasta el punto de ser uno de los grandes introductores de la iusfilosofía que se hacía afuera, sobre todo en Alemania. Cuando UnAmuno fue confinado en Fuerteventura, Roces lo acompañó a Madrid, desde donde el sabio seguiría viaje a su destino. Acto seguido, el romanista fue sancionado.

Conforme fueron pasando los años, las críticas contra la dictadura aumentaron de tono y a partir de 1928, con la ley Callejo, que reformaba la Universidad, la protesta se 
volvió casi unánime. Por eso E. CALLejO DE LA CueSTA, catedrático de Derecho natural y ministro de Instrucción Pública entre 1925 y 1930, tiene mala prensa en los libros de historia, pues le corresponde el triste honor de ser el causante de la rebelión de la Universidad y hasta del consenso que se produjo contra la dictadura. Realmente estuvo implicado otro filósofo del Derecho también citado, que ocupaba el cargo de Director General de Enseñanza Superior y que, al parecer, fue uno de los inspiradores de la ley, W. González Oliveros. De los dos se puede decir lo mismo que de Primo de Rivera, que les corresponde «el dudoso mérito» de conseguir que «la práctica totalidad de la clase intelectual a finales de la década de los veinte» se aliara contra el régimen, pues no tuvieron ningún tacto para resolver la situación sino, al contrario, para empeorarla cada vez más. Volveremos a encontrar a ambos filósofos del Derecho ocupando relevantes cargos políticos durante el régimen de Franco. No digo que la ley Callejo, de mayo de 1928, no pretendiera atajar algunos males de la Universidad, pero consiguió justo lo contrario. El artículo que desató las iras de los estudiantes y de muchos profesores venía a reconocer la enseñanza privada y se interpretó como un paso para la privatización de la enseñanza universitaria. En fin, creo que nunca en la historia de la Universidad española se produjo semejante sublevación, que duraría más o menos un año y que se saldó con la victoria de los estudiantes y la retirada de la ley. En la revuelta también participaron profesores, estando entre los más significados algunos de Derecho, como W. Roces, JimÉNEZ de ASÚA o L. RECASÉNS.

Entre los juristas, como entre la mayoría de los intelectuales, se prodigaron los ataques contra la dictadura. De hecho, TuÑón DE LARA reconoció que una de las tendencias críticas con Primo de Rivera basó sus censuras en «el normativismo jurídico» (1982, pp. 184-185), reconocimiento que significaba la existencia de un frente opositor compuesto por juristas, frente que efectivamente existió. ¿Cuáles fueron los argumentos de los profesionales y los teóricos del Derecho contra la dictadura? De diverso signo: hubo quien apeló a los principios de Derecho natural para atacar el orden político establecido, pero también hubo quien se valió del instrumental kelseniano para hacerlo. Los argumentos que más utilizaron los juristas contra la dictadura, sin embargo, provenían de STAMmLER. Según su concepción el Derecho era «un querer entrelazante, autárquico e inviolable», notas éstas que no se extraían, no se podía extraer, de la experiencia jurídica sino que eran lógicamente previas a ésta, precisamente las que hacían que esa experiencia fuera jurídica. Dicho de forma llana lo que STAMMLER decía de forma oscura, el Derecho era una forma de ordenar no la vida interior de los individuos sino la convivencia humana (entrelazante), caracterizado por tanto por su finalidad (voluntad, querer), por el carácter imperativo de sus normas, que se imponían a sus destinatarios aunque no lo quisieran (autárquico), y por permanencia y uniformidad (inviolable) (STAMMLER, 1930, pp. 63-122).

El más stammleriano de los profesores españoles de Derecho por aquel entonces, el romanista W. ROCES, utilizó a su maestro para condenar la dictadura, de la que ya sabemos que él mismo fue un no disimulado y muy activo enemigo. En el artículo de 1924 que dedicó al concepto de Derecho, se fijó en la última de las notas características que exigían al Derecho, la inviolabilidad, que a STAMMLER le servía para distinguir lo que era un orden jurídico de lo que era mera arbitrariedad, y a ROCES, además, para afirmar claramente que la dictadura española no era un régimen jurídico (1924, p. 416). 
Representante de la crítica que podemos llamar iusnaturalista fue Á. OssoRiO Y GALLARDO, político conservador, jurista eminente, introductor de la ideología democristiana en España y, curiosamente, un monárquico que, a consecuencia de los acontecimientos políticos, diría de sí mismo que no tenía rey. Ossorio fue uno de los más beligerantes contra Primo de Rivera. En 1925, en un artículo que tituló «Retorno al absolutismo», y sin hacer referencia al caso español sino al italiano, dijo que se vivía una época en la que no combatían diversas concepciones del Derecho entre sí, sino en la que había entrado en crisis la misma existencia del Derecho, negado tanto por comunistas como por fascistas. Que se refería también a lo que ocurría en España parece claro, ya que dijo que la dictadura resultaba un régimen jurídico político respetable, siempre que fuera «ejercida por tiempo contado y a nombre de una honda necesidad nacional». Además, el Derecho se caracterizaba por poseer autoridad, y si ésta faltaba, aquél desaparecía. Pero — se preguntaba—, « ¿qué es la autoridad sino la función garantizadora de las libertades? Si no es eso, será una función de arbitrariedad» (1925, pp. 534, 539 y 543). Detrás de semejante condena aparecía el Derecho natural, que era el que otorgaba autoridad al positivo, pero también STAMMLER otra vez, obviamente.

OssoRio también dirigió aquellos años un proyecto editorial que dedicó a combatir la dictadura. Me refiero a los Estudios Políticos, Sociales y Económicos, editorial que publicó libros muy interesantes. Baste citar el libro de ROMERO OTRAzO que llevaba por título Sentido democrático de la doctrina política de Santo Tomás (1930), en el que el sacerdote pintaba un Aquinate poco menos que republicano. En el ámbito filosófico jurídico universitario, representante de esa dirección sería A. MENDIZÁBAL, el catedrático de Oviedo, que también se enfrentó al régimen dictatorial y, en breve, a la monarquía. En 1926 obtuvo plaza en la Universidad asturiana, desde la que participó en el movimiento antidictatorial. Ante los graves sucesos que se habían producido en la Central y el cierre de ésta que había decretado la autoridad gubernativa, la Facultad de Derecho de Oviedo decidió elevar una carta al dictador, unánimemente votada por todo el claustro. Hoy sabemos que fue redactada por el catedrático de Derecho natural, que acababa diciendo, en clara referencia a Primo de Rivera, que los profesores universitarios miraban «con asombro la intromisión de una cierta política en la entraña misma de la vida universitaria, de la que algunos demuestran tener una concepción absurdamente castrense» (por ejemplo, en LÓPEZ-REY, 1930, pp. 179-183).

Llegados a este punto, en el contexto de la lucha universitaria contra la dictadura, hay que hacer referencia a un joven que ya ha sido citado en este trabajo y que estaba llamado nada menos que a renovar la Filosofía del Derecho española, L. RECASÉnS SiCHES. Lo digo porque también él se iba a significar contra el régimen de Primo de Rivera, como veremos. RECASÉNS se había educado en un ideario tradicional pero luego, a través de la Junta, había entrado en contacto con la mentalidad institucionista y últimamente se veía atraído por un pensamiento más moderno, tanto foráneo como nacional. En el extranjero había estudiado con lo más granado del pensamiento jurídico, pero su filosofía sería deudora, sobre todo, de la de ORTEGA. RECASÉns fue un fiel seguidor de ORTEGA, y su filosofía jurídica, adelantémoslo, una aplicación afortunada de la raciovitalista al análisis del fenómeno jurídico. En 1927 obtuvo plaza en la Universidad de Santiago de Compostela. De RECASÉNS nos importan sobre todo dos noticias: por una parte la del papel que jugó en la renovación de la filosofía jurídica; 
por otra, su lucha contra la dictadura y, luego, contra el régimen monárquico y a favor del republicano. Empecemos por su enérgica militancia antimonárquica, pero digamos rápidamente, por si alguien pudiera entender lo contrario, que se trataba de un hombre políticamente moderado, que repudiaba tanto el marxismo y el anarquismo como todo tipo de ultraconservadurismo y cualquier forma de fascismo. Se reconocía personalista, esto es, que afirmaba como valores superiores la dignidad, la igualdad y la libertad, y se sentía cercano a todos aquellos que los compartieran, ya fueran liberales, socialistas no marxistas, democristianos o socialcristianos. Hay constancia de su intensa participación en la protesta, a la que prestó su inteligencia y su elevada formación, pero baste con citar un libro que recogía una ponencia que presentó ante la Academia de Jurisprudencia de Madrid, titulado El poder constituyente (1931), libro en el que condenó la monarquía alfonsina, repudió a Primo de Rivera y a sus sucesores inmediatos por arbitrarios, se opuso a los que querían retornar a la situación anterior al veintitrés y apeló al Derecho natural para elevar un nuevo régimen. Abiertamente se decía, y también el joven catedrático, que España se encontraba viviendo un período revolucionario. ¿En qué sentido? La explicación de RECASÉNS, que señalaba la oportunidad de «ahondar en las entrañas de ese concepto», no deja de ser relevante. Dado que no había Derecho positivo alguno, eso significaba que el único Derecho existente era el Derecho natural, Derecho que establecía que solamente el poder constituyente se hallaba justificado.

Pero no todos estuvieron de acuerdo con el uso de la argumentación stammleriana para desprestigiar al régimen. Años más tarde, otro filósofo del Derecho español, L. LEGAZ, mostró su extrañeza ante ese razonamiento que decía que durante el tiempo de la dictadura España había carecido de Derecho, lo que se debió — dijo- a la identificación entre Estado y Estado de Derecho y protección de los derechos personales. «De otro modo es inexplicable por qué se pone en duda el carácter jurídico del Estado español durante la dictadura» (1934, p. 14). Mas curioso aún es que el mismo hijo del dictador, José Antonio Primo de Rivera, por lo demás un jurista preparado, cuando asumió la defensa de su padre también utilizara argumentos de STAMMLER, pero para defenderlo (1964, pp. 15-36). Vale José Antonio como ejemplo del dato de que los juristas cultos de entonces conocían al neokantiano y utilizaban sus razonamientos, a veces con pretensiones distintas.

Pero hay que volver otra vez a RECASÉNS porque poco tiempo antes de que apareciera el libro referido sobre El poder constituyente, en 1929, se publicaría otra obra suya que va a tener una tremenda importancia, ahora para la filosofía académica del Derecho. Se subtitulaba La Filosofía del Derecho en el siglo XX (y, aun con omisiones significativas, pues se ceñía casi por completo al ámbito germánico, cumplió dos misiones: por una parte hacía la crónica de la filosofía jurídica europea de esos treinta años que estaban a punto de finalizar y, por tanto, ofrecía una visión de conjunto, y por otra parte presentaba a la filosofía jurídica española un plan a seguir, un proyecto de investigación, el de estudiar todo aquello que más allá de nuestras fronteras estaba vigente. Bastará poco tiempo para que los jóvenes iusfilósofos lo vean y se pongan cerebros a la obra. A eso se le llama hacer filosofía a la altura del tiempo, o poner las bases para hacerla. Ése era el proyecto Recaséns. Pero aparte del programa a seguir que el joven iusfilósofo presentaba a sus compañeros y, sobre todo, a quienes en un futuro 
próximo vayan a dedicarse a la filosofía jurídica en España, a estas alturas ésta sigue básicamente dos direcciones: la escolástica y la neokantiana, sobre todo, por ahora, en la variante de STAMMLER, aunque pronto se incorporarán nuevas tendencias, tanto neokantianas como de otro signo. Si a ello unimos el influjo de ORTEGA, el mapa está trazado (GIL CREMADES, p. 43). Caía la monarquía y se abría un tiempo nuevo, también para la Filosofía del Derecho.

\section{EL TIEMPO REPUBLICANO: UNA FILOSOFÍA JURÍDICA PLURALISTA (1931-1936)}

«El cambio de régimen y la proclamación de la República fue una fiesta para la inmensa mayoría de los intelectuales españoles que habían pasado de la beligerancia contra el dictador al repudio de la secular institución monárquica» (Tusell y QueIPO DE LLANO, 1990, p. 255). Por supuesto no fue el único, pero creo que entre los filósofos del Derecho el mejor representante de esa actitud, o el más importante, el que además participó en el primer gobierno republicano, nada menos, fue L. RECASÉNS. Conforme al reparto de carteras que los dirigentes republicanos habían llevado a cabo tras el Pacto de San Sebastián, a Miguel Maura, el jefe político de RECASÉNs, le correspondió el poco deseable Ministerio de Gobernación, con lo que le nombró Director General de la Administración Local, cargo desde el que el iusfilósofo participó en relevantes gestiones y tareas tendentes a consolidar la naciente República. Duró poco, en cualquier caso, pues su destino estaba vinculado al de Maura, que no tardó mucho en dimitir. Luego fue elegido diputado por la provincia de Lugo, participó en la elaboración de la Constitución por medio de diversas enmiendas que presentó y después, más intensamente aún, en la de la ley del Tribunal de Garantías Constitucionales. Pero no sólo se dedicó a la política, pues siguió desempeñando el papel de modernizar la filosofía jurídica española.

La llegada de la República coincidió con diversos acontecimientos relativos a la Filosofía del Derecho: con el fallecimiento de L. MENDIZÁBAL; con el acceso a la cátedra de LuÑo PEÑA, que provenía de la escuela que aquél fundara; con el traslado de RECASÉNS a la Central. Si cabe distinguir entre la docencia y la investigación, de la primera hay que decir que ya en 1930 se había derogado la modificación del plan de estudios de Callejo y suprimido la asignatura de Derecho natural, y ahora la República, rápidamente, establecía una Introducción a la Filosofía en el curso preparatorio y una Filosofía del Derecho al final de la carrera. En cuanto a la investigación, a la altura de 1933 un joven iusfilósofo, L. LEGAZ, se quejaba de la «escasa bibliografía filosófico jurídica» que se producía en España (1933a, p. 106), si bien es verdad que los libros y artículos que se dedicaban a estos estudios no dejaban de aumentar.

Veamos ahora cómo se desarrolló en estos años la nueva Filosofía del Derecho que se iba implantando en España y cuál fue el desarrollo de la filosofía que podemos llamar tradicional. En cuanto a la primera, al que llamo proyecto Recaséns, véase la opinión del propio RECASÉNS cuando, muchos años más tarde, se refiera las transformaciones de la disciplina durante este periodo: «Aparece una nueva generación de iusfilósofos, la mayor parte de ellos entrenados en Alemania, pero con un espíritu 
crítico para discernir, remodelar, renovar, e incluso superar las enseñanzas recibidas en universidades germánicas», y luego cita junto a él a L. LEGAZ y LACAMBRA, J. MEDINA Echevarría, A. Luna García, F. E. González Vicén, M. García Pelayo, J. Corts Grau (1964, p. 12).

Curiosamente, el primer libro que permite observar la ascendencia de RECASÉNS es uno que no se integraría en ese proyecto que encuentra su punto de partida en las Direcciones contemporáneas del pensamiento jurídico. Digo esto porque la tesis doctoral de F. GONZÁLEZ VICÉN, un iusfilósofo que va a alcanzar enorme prestigio en el futuro, tesis que apareció publicada en 1932, llevaba por título Teoría de la revolución, cuando RECASÉNS ya había apuntado la conveniencia de estudiar ese concepto que se utilizaba para referirse a la instauración republicana. En el libro de GONZÁLEZ VICÉN se notaban los influjos neokantianos («Vamos a estudiar la revolución, prescindiendo de todas las revoluciones», decía), el influjo de KELSEN a la hora de concebir el orden jurídico, el influjo y la justificación del socialismo, sin que eso obstara para que llamara «personalidad fecunda y mente privilegiada» a TOMÁS DE AQUINO, o «formidable iusnaturalista» a F. SUÁREZ. Al final, inevitablemente, se preguntaba si la revolución era lícita y, en sede teórica, respondía rotundamente: «Ello depende tan solo de un factor de hecho. De que los atentados contra los postulados sustanciales de la personalidad se verifiquen de un modo "general" y como "sistema". Lo que importa más aún es que casi al comienzo de la tesis había hecho un llamamiento a las clases dominantes para que modificasen "todo el edificio jurídico actual" y establecieran un nuevo Derecho que permitiera, por una parte, que todos los ciudadanos alcanzasen mejores condiciones de vida y, por otra, que cada uno desarrollara libremente su personalidad» (GONZÁLEZ VICÉN, 1932, pp. 37 y 149). Un buen trabajo que, en breve, se daría de bruces con la realidad, con la revolución de octubre de 1934. Conforme al criterio que manejaba F. GONZÁLEZ, ¿sería legítima aquella revolución?

Casi ningún filósofo del Derecho, que yo sepa, se ocupó de analizar el crucial suceso. Sólo quien lo sufrió en propia carne, hasta el punto de que estuvo a punto de perder la vida a manos de los revolucionarios y al final la salvó milagrosamente, A. MENDIZÁBAL, el catedrático de la Universidad de Oviedo, hizo un análisis que muchos consideraron sorprendente (2009, pp. 123-130): condenó tanto la frustrada revolución como los excesos de la represión, a la vez que advirtió de que había llegado el momento de que todo cambiara, empezando por «la actitud de los poderosos hacia los humildes» (1934b, p. 73). Los demás guardaron silencio, aunque no sea difícil imaginar cómo lo juzgaban. Durante el tiempo republicano, varios filósofos del Derecho estuvieron vinculados con quienes desde Acción Española luchaban contra la República (Puigdollers, GonZÁlez Oliveros, Corts Grau, que alcanzará la cátedra durante estos años); otros se integraron en la CEDA, como SANCHO IZQUIERDO; otros, en cambio, pertenecieron a partidos republicanos pero de derechas (L. RECASÉNS, A. MENDIZÁBAL, L. LEGAZ, quien el mismo año de la revolución publicaba su estudio sobre el Estado de Derecho). Que yo sepa, ninguno perteneció al PSOE ni al PCE (en el que sí militó W. ROCES, que incluso participó en la revolución) ni a ningún otro partido de izquierdas. Quizás B. RAmOS se adscribía a una ideología izquierdista, mas no lo expresaba, creo. Quizás también los jóvenes y preparados MEDINA ECHEVARRÍA y GONZÁLEZ VICÉN, pero tampoco tomaban una opción partidista. En términos generales, los filósofos del Derecho seguían siendo políticamente conservadores, aunque el 
término poco dice, pues la distancia entre unos y otros (entre RECASÉNS y GONZÁLEZ Oliveros, por poner un ejemplo) era abismal. De nuestros protagonistas, por lo demás, algunos participaron en la vida política. Ya sabemos de RECASÉNS, que primero fue Director General de la Administración Local, luego diputado por la Derecha Liberal Republicana, pasándose posteriormente, tras las segundas elecciones, al Partido Radical Demócrata de Diego Martínez Barrio, que acabaría convirtiéndose en la Unión Republicana, con la que sería Subsecretario de Industria y Comercio en el gobierno del Frente Popular. Diputado por la CEDA sería SANCHO IZQUIERDO, mientras que LEGAZ lo intentó por el Partido Republicano Conservador, pero no obtuvo escaño.

Pero aunque esas noticias tengan importancia, hay que volver al proyecto Recaséns y referirnos a un acontecimiento doctrinalmente crucial. Por aquellos años RECASÉNS había aconsejado a un joven aragonés vinculado a la escuela de MENDIZÁBAL, a L. LEGAZ, que se ocupara en su tesis con la escuela de Viena, consejo que éste seguiría. También le recomendaría nada menos que ante el mismo KELSEN y así, en 1930, LEGAZ ya se encontraría en Viena poniendo fin a su estudio (1971-1972, pp. 77-78). Poco después aparecería la tesis, en la que veía que la admiración del joven discípulo español por el maestro era infinita: «Considero el advenimiento de la doctrina kelseniana como un hecho que para la filosofía jurídica no es menos importante que la crítica kantiana para la filosofía pura», decía. Pero le veía la misma deficiencia que apuntara RECASÉNS, que no era una filosofía completa sino parcial, que dejaba a un lado las cuestiones ontológicas y axiológicas (1933b, pp. 15-16). No es extraño que más adelante reconozca que su posición se hallaba en una «línea semejante» a la de RECASÉNS (1964, p. 173).

En este punto, cuando ha aparecido L. LEGAZ en escena, hay que hacer referencia a su personalidad, pues se iba a convertir en el filósofo del Derecho español más importante del siglo XX. Otra cuestión es la de cómo se valoren sus opciones políticas o sus actuaciones académicas, pero no se puede negar el enorme significado que tuvo para esta rama del saber. Hay que advertir también, incluso aquí, que aún está por escribir su biografía (no sólo) intelectual. Como RECASÉNS, LEGAZ era un joven intelectualmente muy bien dotado y con una preparación excepcional, aunque su pensamiento evidenciaba entonces cierta tendencia al sincretismo que, con el tiempo, además, se agudizaría. Su carrera fue brillante: en 1935 obtuvo la cátedra de La Laguna y luego pasó a la de Santiago de Compostela. En lo doctrinal provenía del pensamiento cristiano, lo que significa que tuvo que existir cierto choque intelectual cuando se encontró con el neokantismo alemán, y cierta ruptura, y se sentía también muy atraído por el sociologismo tipo ORTEGA y por las nuevas corrientes personalistas cristianas. En fin, todo le llamaba y en todo sabía ver alguna originalidad o alguna idea interesante. Incluso es difícil determinar si se adscribía al positivismo o al iusnaturalismo. Supongo que depende, según se mire: por tradición era un iusnaturalista, pero su última formación había sido positivista. En los actos de la oposición en la que ganó la cátedra vino a decir que ni uno ni otro: «No negamos la existencia de los contenidos ideales que constituyen ese complejo normativo que recibe tradicionalmente el nombre de Derecho natural; lo que negamos es que le convenga realmente el nombre de Derecho». Pero luego abominó del positivismo: «la repugnancia que inspira el positivismo no es tanto por no reconocer más que el Derecho positivo, como por su negación de toda suerte de valores trascendentes y objetivos». 
Otro trabajo que creo que se puede incluir en el proyecto ReCASÉns lo escribió J. MEDINA ECHEVARRÍA, que aunque acabará dedicándose con éxito a la sociología, comenzó su andadura intelectual en el ámbito de la Filosofía del Derecho. Ya había obtenido plaza de catedrático en Murcia cuando apareció publicada su obra La situación presente de la filosofía jurídica (1935) que era otro panorama de la última Filosofía del Derecho. La filosofía existente entonces era — decía- filosofía de la crisis; en diversos sentidos, pues tanto la filosofía se hallaba en crisis, como la vida toda, tal como había sido conocida hasta entonces: crisis política, del liberalismo y del Estado de Derecho y, a su vez, auge de las dictaduras; crisis de la economía, con la quiebra o las transformaciones del sistema capitalista; crisis del Derecho mismo como forma de vida. Ése era el diagnóstico, pero habría que ver las soluciones filosóficas que últimamente se habían dado. MEDina distinguía entre el idealismo dualista y normativista, que tenía como principales representantes a los neokantianos pero también a fenomenólogos y empiristas, el idealismo objetivo, que hallaba su mejor ejemplo en los neohegelianos, aunque también cabían aquí los institucionalistas, y el naturalismo, que incluía a los marxistas y a los sociólogos y filósofos de tendencia sociologista. Además, habría que incluir por separado a los irracionalistas, cuyo último y más destacado representante para la Filosofía del Derecho era JSAY. Por fin, MEDINA presentaba otra clasificación de la filosofía jurídica hecha desde la política y, aunque usara otra terminología, en el fondo distinguía entre tendencias comunistas y fascistas, liberales y socialistas. La Filosofía del Derecho, desde luego, no era ajena a la preocupante situación política de España y de Europa toda.

También en 1935 se produjo otro suceso doctrinal enormemente relevante. E. GÓMEZ ARBOLEYA, un joven en el que nada menos que García Lorca tenía puestas sus esperanzas para que se dedicase a la literatura, esperanzas que defraudaría, y que había sido pensionado por la Universidad de Granada para ampliar estudios en Berlín, leía su tesis doctoral sobre H. HELLER. HeLLER era uno de los grandes representantes de la filosofía del Derecho y del Estado del periodo de entreguerras, y en España era especialmente conocido pues era judío y, huyendo del nazismo, recaló en Madrid, donde al poco falleció. La tesis de GÓMEZ ARBOLEYA ha sido suficientemente estudiada (MESAS DE ROMÁN, 2003), pero importa señalar lo que apuntaba, que el formalismo que se había adueñado de la teoría jurídica resultaba insuficiente y que contra él se habían alzado SMEND, desde el liberalismo, SCHMITT, desde el totalitarismo, y HeLLER desde un socialismo de corte humanista que repudiaba, muy especialmente, el positivismo ideológico, «porque hoy nadie está en situación de creer que todo lo que dicta el poder legislativo sea Derecho justo «a causa de una predestinación metafísica» (1982, p. 123). Lo curioso del caso es que la leyó en 1935 pero no se publicó hasta 1940 y así, aunque sea cierto que hay algunas diferencias entre el texto de la tesis y el publicado, resulta un metafórico puente entre lo que se hacía en la etapa republicana y lo que se hizo en el franquismo.

Ahora que ha aparecido el nazismo en escena hay que preguntarse por su filosofía jurídica y por la recepción que se le dispensó en España. Si la última Filosofía del Derecho española era deudora de la alemana, la llegada de los nazis al poder transformó todos los sectores de la vida, incluso éste del pensamiento, y tuvo que resultar sorprendente para nuestros protagonistas. Los filósofos del Derecho españoles dieron 
prontas noticias tanto del acontecimiento de la llegada al poder del nazismo como de su filosofía del Derecho, que en general enjuiciaron negativamente. El primero que se hizo eco y advirtió contra lo que estaba ocurriendo en Alemania fue A. MENDiZÁbal que juzgó intolerable tanto el nuevo régimen como su filosofía (1933). Un compañero suyo, en cambio, GONZÁLEZ Oliveros, desde las páginas de Acción Española valoró favorablemente tanto la nueva situación como la nueva ideología; acertaba a ver en ella «un movimiento esencialmente antiliberal», pero a la vez decía que se trataba de «la rebelión del pueblo corporal y espiritualmente sano» ( $\mathrm{j} !)$ contra la «siniestra degeneración» socialista (1934, pp. 331 y 333). En cualquier caso, el fascismo alemán resultaba tan revolucionario que quería transformarlo todo, hasta la Filosofía del Derecho. A la descripción del nuevo pensamiento jurídico dedicó LEGAZ (1934b), siempre atento a las novedades, un monográfico: se trataba de una teoría racista del Derecho, es decir, que lo entendía como uno de los productos espirituales de la raza y cuyo fin debía ser, precisamente, la satisfacción de sus necesidades biológicas, conservar la pureza del pueblo racialmente considerado. Pronto habría noticia en España de las medidas que los nazis adoptaban contra las otras razas, lo que hizo que algún filósofo del Derecho se declarara militante antifascista. Me refiero de nuevo a RECASÉNS, que junto a otras personalidades de la intelectualidad republicana (UnAmUNO, JimÉNEZ DE AsúA y MARAÑÓN) fue artífice de un manifiesto donde se pedía la creación de un Comité de intelectuales conscientes que colaborara en la organización de la ayuda a «las víctimas del terror nazi». Poco después, con motivo de la constitución de ese comité, en un acto que se celebró en el Ateneo madrileño, intervino junto con JIMÉNEZ DE AsÚA, precisamente alertando contra la barbarie del nazismo (ARRARÁS, 1969, p. 182). Por cierto, llegados a este punto hay que decir que a RECASÉns le cabe el honor de haber sido uno de los intelectuales más atacados por los fascistas españoles. Justo antes de la instauración republicana, Ramiro Ledesma le insultó de forma especialmente grosera y malintencionada (1986, pp. 73-74). En cuanto a José Antonio Primo de Rivera, aunque se respetaran mutuamente, y hasta le admirara el jefe de la Falange por sus conocimientos, no dejó de amenazarle en las mismas Cortes republicanas: «iTenga mucho cuidado!», le dijo en un agrio debate (Diario de Sesiones de las Cortes, 275, p. 11255). No había que tomar a broma esas palabras.

Pero al fin y al cabo el fascismo tenía poca o ninguna importancia en la Filosofía del Derecho. Hay que hacer referencia, en cambio, a la filosofía escolástica, que siguió cultivándose durante este tiempo, aunque - como dijo LEGAZ - careciera de «una figura de resonancia a la vez popular y universal: no hay ningún Balmes ni ningún Donoso Cortés» (1947, p. 341). En el ámbito jurídico, esta dirección mantuvo el sentido y los tópicos implantados tradicionalmente aunque — me parece- hubo algunos intentos reformistas. Por una parte el de CORTS GRAU, catedrático en 1935, que introduce la doctrina de la institución, de RENARD (con quien estudió en la Universidad de Nancy en el curso 1930-31), «que viene a ser en definitiva —como decía el mismo CORTS- la última valoración jurídica de la noción tomista del bien común», observando el Derecho como un fenómeno práctico, indisoluble de la moral y vinculado a la satisfacción de las necesidades humanas, necesidades que son las que originan realidades supraindividuales, cuales la familia, la nación, la empresa, la Universidad o el Estado (1934). Tras la guerra, el institucionalismo tendrá continuación. Más reformista fue A. MENDiZÁbal, que se convirtió en el representante en España de un catolicismo 
democrático y progresista, identificado con el de MARITAIN en Francia. Ya vimos que durante los años de la dictadura, MENDIZÁBAL se dedicó al estudio doctrinal de la filosofía con la que se identificaba, la tomista. Ahora comenzó a aplicar esas ideas a la práctica, aunque seguro que muchos pensarían que se trataba de una aplicación por lo menos peculiar. Fijémonos en los temas que trata y en cómo lo hace. Por una parte, ya sabemos que es uno de los primeros que da a conocer en España el pensamiento de fascismo alemán, que condena tajantemente; por otra parte, también expone y critica la doctrina comunista (1934a). A la vez traduce a STURZO (1935), con lo que se hace eco de una ideología democristiana y de la teoría del totalitarismo, una categoría que engloba y muestra lo que de común tienen el fascismo y el comunismo.

Por lo visto hasta aquí, creo que se puede concluir que la filosofía jurídica que se hizo en el tiempo republicano gozaba de buena salud. Por una parte, la especulación se caracterizaba por el pluralismo (influjos positivistas, neokantianos, sociologistas, al lado de otros más tradicionales); por otra, el acceso a la academia se caracterizó por ese mismo pluralismo, cuando durante la etapa republicana consiguieron la cátedra profesores de variadas tendencias políticas y filosóficas: MEDINA, LEGAZ o GONZÁLEZ VICÉN, pero también LUÑO o CORTS. Éste era el muy saludable estado de disciplina de la época; con razón se ha hablado de una «edad de plata iusfilosófica» (GIL CREMADES 1987, p. 564).

Si en cierta forma esta etapa comienza con las Direcciones, de RECASÉNS, podemos ponerle fin con sus Estudios de Filosofía del Derecho (1936). Origen de su manual iusfilosófico (1986), uno de los más representativos del siglo Xx, muestra todos los influjos de éste, que lo convierten en un libro a la altura del tiempo. Precisamente a estas alturas RECASÉNS es —como con razón dirá más adelante GÓMEZ ARBOLEYA en su clásico «Sociología en España»- la «cabeza dirigente» de la Filosofía del Derecho española (1982, p. 689). Aún le queda una dilatada carrera en México, y aunque hará nuevas e interesantes aportaciones, creo que a partir de este momento (del que no se pueden dejar las circunstancias políticas aparte) el testigo lo va a tomar L. LEGAZ, que ya estaba preparado para convertirse en el nuevo motor de la especulación iusfilosófica de acá. En cuanto al libro de RECASÉns, en lo tocante al concepto del Derecho se veía su dependencia de ORTEGA y de STAMMLER, sobre todo; y por lo que se refiere a la cuestión valorativa, el influjo era de la filosofía de los valores y de la escolástica. En este punto reivindicó la moderación frente al extremismo. Y entonces estalló la guerra.

\section{GUERRA CIVIL Y FILOSOFÍA DEL DERECHO (1936-1939)}

El acontecimiento más sangriento y lamentable que se produjo en la España del siglo XX, la guerra civil, afectó a todos los ámbitos de la vida colectiva, incluso al tan específico del pensamiento filosófico jurídico que ahora nos ocupa. Aunque convenga matizar el juicio, desde la perspectiva de éste la contienda supuso una ruptura innegable. Como regla general los pensadores que podemos llamar escolásticos tomaron la opción del bando alzado en armas contra la República. En efecto, M. SANCHO IzQUIERDO, E. LuÑo, M. Puigdollers o W. GonZÁlez Oliveros se comprometieron con el contendiente antirrepublicano. Al contrario, y también como regla general, los que no 
pueden ser tachados de tradicionales no se adhirieron a ese bando: L. RECASÉNS, B. Ramos o J. Medina. Pocas excepciones, por tanto: la de Legaz y la de Mendizábal, que además pertenecían al mismo grupo, la escuela aragonesa de Derecho natural.

L. LEGAZ se puso al servicio de los sublevados y llevó a cabo una importante labor ideológica (TuÑón DE LARA, 1982, p. 252; SueIro y DíAZ-NosTy, 1985, p. 51). La pregunta es inevitable: ¿por qué LEGAZ se adhirió al bando de Franco? Realmente esta pregunta puede hallar cabal respuesta. La que ya no tiene explicación es esta otra: ¿por qué LEGAZ se convirtió en uno de los más importantes ideólogos del fascismo español? Para el que ya era catedrático de la Universidad de Santiago aquellas primeras jornadas de la guerra tuvieron que plantear un grave dilema. En términos políticos, el calificativo que mejor le cuadraba era el de liberal conservador. Defensor del Estado de Derecho y de la democracia, que yo sepa nunca se había pronunciado contra la República. Al contrario, había militado en un partido de derechas pero radicalmente republicano. Como pronto se sabría, compañeros muy cercanos de LEGAZ no quisieron tener nada que ver con el alzamiento. Por afinidad de ideas, los casos más representativos y cercanos son los de L. RECASÉNS y A. MENDIZÁBAL, cuyas posturas no fueron coincidentes, aunque es cierto que ambos se negaron a apoyar tanto a unos como a otros y que sin duda repudiaron más a los sublevados que a los leales a la República, pues al fin y al cabo ellos mismos eran republicanos. Por lo demás, como éstos, LEGAZ era católico, y si bien es verdad que la inmensa mayoría de los católicos españoles tomaron la misma opción, los propios RECASÉNS y MENDIZÁBAL, entre otros, demuestran que no había de ser necesariamente así. Aun tratándose de un católico, por tanto, casi todos los datos apuntan a una decisión favorable a la República o, en todo caso, desfavorable para los sublevados. Quizás lo suyo, como hizo RECASÉNs, descontento con unos y con otros, y temiéndose lo peor, hubiera sido la huida. Sin embargo, LEGAZ resolvió colaborar. ¿Por qué? L. LEGAZ era, sobre todo, un estudioso, un hombre pacífico y moderado, en medida alguna extremista. Supongo que la dirección que había tomado el régimen desde febrero no era de su agrado, pero que tampoco la consideraría suficientemente grave como para tomar las armas. Empero, se producirían al menos dos circunstancias que iban a hacer que apoyase la sublevación: se encontraba en Galicia y allí el alzamiento fue un éxito inmediato y, además, en breve tiempo iba a contraer matrimonio. En la decisión que LEGAZ tuvo que tomar (lo que no podía hacer era abstenerse), ambos factores inclinaron la balanza por una opción con la que no podía sentirse entusiasmado... Pero se convirtió en un entusiasta y, contra todo pronóstico, se radicalizó (i!). Como todos los que tuvieron que optar por unos u otros, aquella decisión le marcaría la vida.

La otra excepción fue la del ya citado A. MendizÁBAL, que aun siendo un fiel tomista repudió a los militares, a la vez que se negó a apoyar a los republicanos. Su caso tiene más interés todavía, porque su postura tuvo algo de heroica. El estallido de la guerra le cogió en el extranjero y, afortunadamente, no pudo volver, con lo que se quedó en Francia. Sobrevivió ayudado por MARITAIN y los suyos y, mientras tanto, puso en marcha el Comité español por la Paz Civil y Religiosa en España, organismo que desarrolló interesantes actividades (intentos de organización de treguas, de canje de prisioneros, de conmutación de penas, etc.) aunque, por desgracia, siempre sin éxito. De estos años destaca un libro suyo sobre la historia contemporánea española, Los 
orígenes de una tragedia, en gran medida ignorado en España (apareció en francés y se tradujo prontamente al inglés y al sueco, pero aún hoy no se ha traducido al castellano), sólo conocido por el importante prefacio de MARITAIN, con el que se situaba en un terreno equidistante de unos y otros, cuando era — decía - una «guerra de exterminio» (MENDIZÁBAL, 1937, p. 50).

Ahora que cuento las peripecias de LEGAZ y de MENDIZÁBAL, que ya está dicho que pertenecían al mismo grupo, el aragonés, y que compartían intereses y perspectivas, siendo MENDIZÁBAL, sin lugar a dudas, en lo filosófico un escolástico y en lo político un democristiano, y teniendo LEGAZ también algo de escolástico y de democristiano, aunque su postura fuera más compleja que la de aquél e incluyera más tendencias; ahora hay que narrar un triste suceso que traería consigo nada menos que MOUNIER se fijara en ellos. Además de tener otras cosas en común, MENDIZÁBAL y LEGAZ coincidían en el grupo de Amigos de Esprit, que debió de constituirse a fines de 1935, impulsado por José María Semprún, profesor también de Filosofía del Derecho e inseparable amigo de Alfredo. La completa transformación de LEGAZ se puede ver aquí, pues de militar en el personalismo católico pasó a combatirlo. Es obvio que el joven filósofo del Derecho admiraba a MARITAIN, lo que se puede constatar leyendo algunas obras suyas anteriores a la guerra. Ahora, sin embargo, se convirtió en su enemigo político y filosófico. Se trataba del pensador católico más importante que había levantado su voz contra los sublevados. También Mounier, pero seguramente el otro filósofo francés tenía más predicamento en el mundo católico. El carácter inequívocamente democrático, antifascista, del maritainismo lo hacía especialmente odioso a los ojos de los sublevados, que tuvieron que soportar que los republicanos publicaran un panfleto, que en gran medida contenía el prefacio que MARITAIN escribió para el libro de MENDIZÁBAL antes citado, con el título de Los rebeldes españoles no bacen una «guerra santa». Con razón pensó LEGAZ que su ataque tenía que ir dirigido contra tan relevante tomista, que ponía en duda los argumentos de los alzados en armas y que, como sabemos, se negaba a dar la consideración de cruzada a la guerra civil española. Los artículos que ahora escribió los destinó a ese fin (1937 y 1938), arremetiendo contra los democristianos que criticaban la sublevación: Maritain, Mounier, Sturzo, Mendizábal y Semprún. A los dos últimos, sus antiguos amigos, los acusó por seguir las rutas de la Tercera España y la Pacificación cristiana.

Que yo sepa, MENDIZÁBAL nunca contestó públicamente a su antiguo amigo, pero sí lo hizo SEMPRÚN, que envió una carta a MOUNIER y éste, me imagino que sin querer, dio publicidad a la queja de aquél. Una parte de la carta de SEMPRÚN a MOUNIER se publicó en Esprit (1938). En ella SEMPRÚN identificaba la causa personalista, «manchada de sangre y barro - decía— (porque no somos ángeles sino hombres)» con la republicana (y así, de paso, contestaba a la crítica de LEGAZ a MARITAIN); a la vez que hablaba de los otros como «los asesinos de tantas pobres gentes inocentes». La otra parte de la carta era privada. MouniER, sin embargo, respondió públicamente a las dos partes de la misiva de SEMPRÚN y, respecto a la segunda, en referencia a LEGAZ, dijo: «Me bastará comprobar que no hay una caricatura más peligrosa del personalismo que el hacer que concluya, de una concepción del hombre "total", en el apoyo del Estado totalitario, y en la defensa de la guerra como "factor de auténtica personalización"; me bastará comprobar esto para borrar el nombre de personalismo de nuestra comunidad» (1938, 
pp. 246-247). Las palabras de MounIER sirven para testimoniar la ruptura que se había producido entre los católicos españoles más avanzados; también la ruptura que se produjo en la academia de la Filosofía del Derecho. El suceso muestra como ningún otro el ambiente que se vivía.

Ahora bien, con la reciente referencia a SEMPRÚn, comprometido siempre con la República, pudiera pensarse que otros apoyos fueron inequívocos. En absoluto; entre los iusfilósofos la negativa a colaborar con los rebeldes no significó necesariamente el apoyo al gobierno republicano. Más en concreto, sólo un filósofo del Derecho optó por la lealtad al régimen establecido, J. Medina EcheVARRía, lealtad que en su caso, como en el de otros profesores universitarios, consistió en irse en misión diplomática, en 1937, para Varsovia, como secretario de la Legación española en la capital polaca. RECASÉNS, en cambio, tras un breve servicio a favor de la República se fue para México, convencido ya no de su neutralidad, sino de que ni unos ni otros le respetarían, lo que sin duda era cierto. En cuanto a B. RAMOS, también se encontraba en el extranjero pero, con buen juicio, no pretendió volver; aunque sí lo intentó más tarde, tras la guerra, sin conseguirlo.

Antes dije que, por lo que se refiere a la opción bélica de los filósofos del Derecho, hubo dos excepciones, pero el caso de F. GONZÁLEZ ViCÉn también es excepcional, además de rocambolesco. El 18 de julio de 1936 se encontraba en Alemania y, curiosamente, decidió volver. La explicación, sin embargo, parece sencilla: su hermano Luis era un alto jerarca de la Falange y, por tanto, Felipe se sentía protegido. No fue así, sin embargo, hasta el punto de que, ya en Sevilla, se le abrió un expediente en el que se le acusaba de ser un extremista de izquierdas y que se resolvió privándole de la cátedra e inhabilitándole para ocupar cargos directivos y de confianza. Ante semejante tesitura, tuvo que huir como pudo con su familia. Pero aparte de las personales peripecias, dramáticas casi siempre, lo que se puede observar es que mientras que hubo bastantes filósofos del Derecho que tomaron la opción por los sublevados, solamente uno se puso claramente del lado de los republicanos, lo que parece indicar el carácter tradicional de la filosofía jurídica española o, si valen estas interpretaciones políticas, su mayoritaria militancia antirrepublicana frente al abstencionismo o la tercera vía de los otros, que a veces también podían ser llamados conservadores, casos de RECASÉNS o de MENDIZÁBAL.

En lo tocante a una labor ideológica, hasta donde yo sé entre los filósofos del Derecho españoles no hubo colaboraciones doctrinales significativas tendentes a justificar la República. En cambio de entre los que se unieron a los alzados en armas algunos se dedicaron a lo que les resultaba más propio, escribir libros y artículos destinados a fundamentar la actuación militar y el hipotético próximo régimen. Baste citar a tres de ellos, los más característicos, para observar la diversidad del contendiente nacionalista: a W. GonZÁLEZ Oliveros, representante de la derecha radical, a M. SANCHO IZQUIERDO, de la conservadora, y otra vez a L. LEGAZ, que ahora se arrogaría la representación doctrinal del fascismo hispano. No es de extrañar que el discurso programático fuera distinto, a veces contradictorio, en los tres casos. Como era de esperar, GONZÁlez Oliveros se distinguió por escribir algunos de los libros más combativos del periodo bélico (1937a y 1937b). Activo colaborador de la dictadura de Primo de Rivera y enemigo declarado de la República, el catedrático de Salamanca 
admitía que sus trabajos eran verdaderas armas dispuestas al asalto en aquella «guerra de ideas» que también era la contienda bélica, advertía contra el espíritu modernista de la Falange y preparaba el ambiente para la unificación de ésta con los tradicionalistas. Entre insólitas invocaciones a Dios y a la patria, no se ahorraba insultos para todos aquellos que consideraba opositores a la causa nacional y enemigos de España (Menéndez Pidal, G. y F. DE los Ríos, Castillejo, Jiménez de Asúa, entre otros muchos). En cambio, aun dentro del exaltado ambiente reinante, SANCHO IZQUIERDO era más moderado, y dejaba ver sus orígenes democristianos a la vez que alababa la ascensión del fascismo italiano. No es extraño que por aquel entonces la preocupación fundamental del aragonés fuera la cuestión social, a la que dedicó varios artículos en los que se podía ver la dependencia del discurso pontificio $(1936 / 1937,1938)$. Por último, L. LEGAZ se dedicó a fundamentar un fascismo español con las modernas doctrinas políticas y jurídicas que surcaban Europa (que no siempre eran fascistas sino, a veces, liberales e incluso socialistas) y que él conocía bien (SCHMiTT, HeLLER, Kelsen, GuRvitch, OrTEgA, entre otros). Es verdad que también provenía de ámbitos católicos, pero en su etapa de formación académica se había educado en la última filosofía continental, a la vez que había optado por un liberalismo personalista que ahora, como vimos, en consonancia con la moda totalitaria, tendría que rectificar. De hecho, el problema al que LEGAZ tratará de encontrar solución entonces, el del tipo de régimen que habría de implantarse, no era ajeno a la cuestión anterior. Que su tesis fuera la del «humanismo totalitario» ya nos dice de sus imposibles intentos conciliadores (1937 y 1938).

Mientras tanto la guerra avanzaba a su final dejando un sinfín de víctimas. Hasta donde conozco, entre quienes se dedicaban entonces a la Filosofía del Derecho no hubo bajas, ni en uno ni en otro bando, aunque Los filósofos del Derecho perdedores no perdieron la vida, pero sí otros bienes de gran valor. Por cierto, también hubo entre los iusfilósofos quien asumió funciones directivas en la Junta Técnica. En concreto, M. Puigdollers fue vocal de la Comisión de Cultura y Enseñanza, organismo que se dedicó a la triste tarea de depurar de elementos desafectos al personal docente universitario. En esa labor también participó SANCHO IZQUIERDO. No es éste el momento de explicar los entresijos de la depuración, pero sí apuntar que todos los filósofos del Derecho que tuvieron que exiliarse fueron sancionados (con las sanciones al uso: la separación de la cátedra y la inhabilitación para cargos públicos) por la citada Comisión: con mejor o peor fortuna, RECASÉNS, MENDIZÁbAL, MEDINA, RAMOS y GONZÁLEZ VICÉN tuvieron que buscar acomodo donde pudieron.

\section{EL FRANQUISMO Y LA FILOSOFÍA DEL DERECHO (1939-1975)}

Mientras tanto, en el interior, daba comienzo una nueva circunstancia, un régimen político que, anómalo, perviviría durante casi cuarenta años de la historia de España y que afectaría a los ámbitos más diversos, también al de la Filosofía del Derecho que se elaboró durante todo ese tiempo. Precisamente la extensión del lapso temporal exige periodificar el franquismo, ahora desde el punto de vista de la filosofía jurídica. Otra vez resulta llamativa la coincidencia entre los periodos de la historia de la Filosofía del Derecho y los periodos de la historia general, de la historia política. 


\subsection{La posguerra: la reconstrucción de la filosofía jurídica (1939-1945)}

La época que siguió a la guerra se caracterizó por una feroz represión, a la vez que se ponían los cimientos del Nuevo Estado. Esta labor constructiva, que tenía que abarcar hasta el más pequeño ámbito de la vida, requería del esfuerzo de todos aquellos que se consideraban partícipes en el proyecto franquista. De los filósofos del Derecho, hubo quienes participaron en los más altos organismos del nuevo Estado. E. CAllejo DE la Cuesta, por ejemplo, formará parte del Consejo de Estado desde poco después de acabada la guerra, siendo nombrado en 1945 presidente del citado organismo. M. PuigDollers será desde después de la guerra y durante muchos años Director General de Asuntos Eclesiásticos. Pero el que asumió responsabilidades más graves en la durísima etapa de la posguerra fue W. GONZÁLEZ OLIVEROS, a quien se le nombró Gobernador Civil de Barcelona en 1939, nada menos, y al que al año siguiente designarían Presidente del Tribunal de Responsabilidades Políticas y Vicepresidente del Tribunal Especial de Represión de la Masonería y el Comunismo. El doble cargo (y su fanatismo) lo convertirán - dice con razón M. Álvaro DuEÑAS - «en uno de los máximos ejecutores de la política represiva del régimen» (ÁLVARO DUEÑAS, 1999; 2006, pp. 107 y 127).

Si nos fijamos en el ámbito del pensamiento, nos damos cuenta de que, tras la guerra, incluso un sector tan particular de éste como el de la filosofía jurídica requería esa renovación que de todo se predicaba. Además, por causas evidentes varias cátedras habían quedado vacantes y deberían ser cubiertas, cuando se necesitaba de pensadores leales — se decía - para elaborar un pensamiento auténticamente español. Así, en primer lugar hubo una academia universitaria formada por los profesores de Filosofía del Derecho, aunque también podríamos incluir aquí a los profesores de otras disciplinas jurídicas (como CASTÁn, DE CASTRO o HERNÁNDEZ Gil, en el ámbito del Derecho civil, por ejemplo). Evidentemente, la academia de la posguerra era un resultado más de la conflagración, por lo que bien puede hablarse de una academia del interior y otra del exilio, «peregrina». Al fin de la guerra, la del interior quedaría compuesta por CALLEJO DE LA CUESTA (que aunque casi no se dedicaría a la disciplina, reingresó en el cuerpo de catedráticos, antes de pasar al Consejo de Estado), SANCHO IzQuiERdo, PUigdollers Oliver, González Oliveros, Luño Peña, Corts Grau y Legaz Lacambra. El número de plazas vacantes, sin embargo, hizo que la academia universitaria tuviera que reconstruirse en estos años y eso explica que se celebraran siete oposiciones a cátedra entre 1940 y 1945. En el acceso a aquellas cátedras se observan claramente influjos políticos, pero no sólo. Es obvio que en la posguerra únicamente ganaron oposiciones quienes no tenían vedado el acceso, pero eso no significa que su nivel intelectual fuera escaso. Al contrario, todos los que obtuvieron cátedra entonces eran —creo yo- de gran valía intelectual: E. Gómez Arboleya, R. PÉrez Blesa, F. Elías de TejadA, J. Ruiz Giménez, E. Galán, S. Lissarrague y A. Truyol.

Pero esas dos academias, la del interior y la del exilio, no eran las únicas, amén de que una tuviera que irse y desapareciera como tal. Quien se enfrente a este periodo se encuentra con otra academia que ya existía anteriormente pero que ahora va a alcanzar singular importancia, la del clero. No hace falta señalar la trascendencia que alcanzó el estamento sacerdotal en aquellos años, ni tampoco cuál era la forma de actuación de 
muchos de los que en él se integraban: instancia última del bien y del mal, era lógico que quienes se consideraban competentes para elaborar la filosofía moral, también se dedicaran a la jurídica, pues aquélla incluía ésta. No sólo juzgaron la iusfilosofía que hicieron los universitarios, sino que elevaron una especulación propia que pretendió convertirse en la ortodoxa. S. RAmírez, T. URdÁnOZ, G. MÁrQuez, J. IRIARTE o M. MARTín son algunos de sus representantes.

Como ya apunté, los conflictos entre una y otra academia existían, aunque muchas veces no se dejasen traslucir. Véase el caso, por ejemplo, de la teoría pura del Derecho (RIvAYA, 2000). Entre los profesores universitarios de la disciplina creo que se puede decir que hubo dos tendencias: la de aquellos que conocían y admiraban la obra de KELSEN, aunque no compartieran sus presupuestos ideológicos, y la de los que, mayores y más tradicionales, no se interesaron por ella. Quienes lanzaron la condena sobre este pensamiento jurídico no fueron ellos sino los que se integraban en la academia clerical. A LEGAZ, nada menos, le advirtieron de que su «simpatía kelseniana» era contradictoria con el propósito de ayudar a la elaboración de una nueva teoría del Estado, pues la tradición católica no era conciliable con la doctrina de KELSEN (IZAGA, 1941, p. 174). La respuesta de LEGAZ, por cierto, sería contundente, advirtiendo al «coro de sus sistemáticos detractores» que muchas de las construcciones kelsenianas ya estaban «definitivamente» incorporadas a la ciencia jurídica, por mucho que le dirigieran «gruesos improperios» (1942, pp. 355 y 371). Pero no sólo se trató de la teoría pura, pues conflictos como éste no fueron infrecuentes durante aquellos años.

No se puede hablar de academia en el caso de otra iusfilosofía que quiso buscar acomodo en la España de aquellos años, la del nacional-socialismo (RIVAYA, 1998b). Un conjunto de revistas, entre las que destacaban Investigación y Progreso y Ensayos y Estudios, se dedicó a propagar el pensamiento del fascismo alemán y, por lo que ahora interesa, el filosófico jurídico. De entre los alemanes, se recibieron trabajos de SCHMitT, que merecería un capítulo aparte, LARENZ, SiEBERT o HEDEMANN, junto a los de otros autores menos conocidos. El momento culminante de la introducción de esa filosofía racista sería el de la traducción (hecha por E. GALÁn y A. TRUYOL) de La Filosofía contemporánea del Derecho y del Estado (1942), de K. LARENZ, que dejó ver la mucha polémica que creaba la ideología nacional-socialista entre nuestros autores (vid. RIVAYA 1998a, pp. 177-184). Aunque la hermandad de ideales nadie la negara, se demostró entonces que el pensamiento alemán y el español de la época no eran conciliables, al menos como regla general. No extraña que fueran quienes se integraban en la academia a la que me referí anteriormente, la de los religiosos, así como los juristas más tradicionales, quienes reaccionaron contra esa iusfilosofía que se caracterizaba fundamentalmente por el culto a la raza.

Visto el panorama, lo más llamativo de la composición de la Filosofía del Derecho española de aquellos años fue que reflejara con tanta fidelidad la realidad política. Tal vez se trate de una clasificación demasiado general, pero necesaria para llevar a cabo un primer acercamiento, la que distingue, en un sentido amplio que habría que matizar, entre «católicos» $\mathrm{y}$ «falangistas». Bajo el primer rótulo englobamos tanto a quienes provenían de la derecha radical como a los que pertenecían a la conservadora, pues ahora entre unos y otros habría más parecidos que diferencias: defensa a ultranza de los dogmas católicos y de la estructura social tradicional, absoluto anticomunismo y 
autoritarismo político. En el segundo rótulo incluimos a quienes formaban parte, no sólo nominalmente, de la Falange, como LEGAZ o LiSARRAGUE. Éstos parecían tener orígenes menos marcados, aunque también conservadores, y hacían gala de un modernismo que a veces, no siempre, era repudiado. Admitían el dogma católico, por supuesto, pero no le otorgaban tanta importancia como los otros. En realidad se podría hacer una graduación de la filosofía de la época atendiendo a la mayor o menor tolerancia con las doctrinas discrepantes: desde PUIGDOLLERS, que decía rechazar el «materialismo, el apriorismo, el formalismo, el fenomenologismo, el existencialismo, el vitalismo..., y todos los ismos que no sean una clara y exacta visión cristiana del Mundo y del Hombre» (1942, p. 12), hasta Galán, Truyol o Arboleya, que aceptaban buena parte de la especulación contemporánea. Ahora bien, que el periodo se caracteriza por la complejidad, además de por un limitado pluralismo, lo demuestra un dato antes apuntado; porque pudiera pensarse que el pensamiento nacional-socialista sería importado por los falangistas, y es cierto que LEGAZ, no así LISSARRAGUE, asumió durante tiempo esa tarea, pero el paradigmático libro citado de LARENZ fue traducido por dos jóvenes, GALÁN y TRUYOL, que no se integrarían en esa órbita sino en la otra, en la «católica».

Por lo que se refiere al acceso a las cátedras de Filosofía del Derecho y Derecho natural, la larvada pugna entre unos y otros estuvo saldada desde un primer momento a favor de los católicos, en concreto a favor de la Asociación Católica Nacional de Propagandistas. En ella se integraba la mayoría de nuestros protagonistas: SANCHO, Puigdollers, Luño, Corts, Elías de Tejada y Ruiz-Giménez. En el pasado Legaz también había pertenecido a la Asociación, pero ahora ya no. Probablemente salvo a LisSARRAGUE, la ACNdeP les otorgó su apoyo a todos los demás que alcanzaron la cátedra en la posguerra. En cualquier caso, el grupo falangista tendría un peso mucho menor en la configuración de la academia universitaria de la filosofía del Derecho de la posguerra (realmente en todas las academias del Derecho, en las que la ACNdeP ejercía mayor control), en buena medida reflejo del menor influjo falangista en los ámbitos del Ministerio de Educación Nacional, cuyo titular (y por tanto quienes tenían acceso a él) controló directamente y durante mucho tiempo el acceso a las cátedras.

Desde el punto de vista de las tendencias filosóficas también habría que hablar básicamente de dos tendencias, la escolástica y la orteguiana, aunque quizás convenga llamar moderna a ésta, pues los influjos no sólo eran de ORTEGA. En principio se ve cierto paralelismo entre esta clasificación y la anterior; o sea, que los «católicos» serían escolásticos y los falangistas, orteguianos o modernos. En efecto, creo que LISSARRAGUE bien podría representar a la Falange orteguiana, mientras que SANCHO, PUIGDOLLERS o RUIZ GIMÉNEZ, por ejemplo, serían representantes distintos de la escolástica católica. Mas, como siempre, la diferenciación no es tan clara. Dejando por ahora a LEGAZ, que merece capítulo aparte, en el caso de LISSARRAGUE no hay que olvidar su esfuerzo por integrar la filosofía católica en su especulación, con sus estudios sobre TOMÁs DE Aquino y Vitoria. Con respecto a GÓMEZ ARBOLEYA, ya se dijo que mostró cierta afinidad personal con el falangismo liberal a lo Laín, pero también que fue por encima de otras consideraciones un pensador cristiano, aunque moderno como demuestran sus estudios sobre la filosofía contemporánea alemana o, más en concreto, sobre C. SCHMITT; y lo mismo cabría decir de GALÁN, y también de Pérez BLESA y de TruYOL. El 
caso de GALÁN es interesante, sobre todo por su evolución posterior que lo llevaría a la extrema derecha, pero también porque en aquel entonces era uno de los jóvenes y bien formados escolásticos que al tiempo estaban influidos por el pensamiento historicista y, más en concreto, por ORTEGA. Además, el GALÁN de la posguerra es un buen ejemplo de que el proyecto de RECASÉNS de introducir la iusfilosofía contemporánea en España no había fracasado; en este sentido, su tesis sobre E. LASK, uno de los principales pensadores de la Escuela de Baden, es paradigmática (GALÁN, 1944). Sin duda TruYOL era más tradicional, pero algo parecido podría decirse también de él. Aun con ciertas alteraciones, por tanto, el programa Recaséns todavía tenía seguidores.

Es cierto que la reflexión filosófico jurídica estaba sometida a férreos límites, pero también que no todo era igual; hasta se puede afirmar — ya se apuntó- que durante aquella primera posguerra existió un limitado pluralismo. Véanse los conceptos de Derecho que se manejaron, que iban desde el de SANCHO, que lo entendía como el «mandato del supremo Rector y Gobernador del Universo» (1943, p. 10), pasando por el de RuIZ GiMÉNEZ, también escolástico pero remozado por la terminología institucionalista (vid. 1944), hasta el muy orteguiano de LISSARRAGUE, para quien el fenómeno jurídico se componía por un conjunto de usos peculiares, tanto por su impersonalidad como por su coactividad e irracionalidad (vid. 1944 y 1948), o el más complejo de LEGAZ, cuya definición merece ser transcrita: «Forma de vida social en la cual se realiza un punto de vista sobre la justicia, que delimita las respectivas esferas de licitud y deber, mediante un sistema de legalidad, dotado de valor autárquico» (1943, p. 161). En la definición de LEGAZ se dejaban ver influjos muy variados. Tras la «forma de vida social» se hallaban ORTEGA, RECASÉNS o GURVITCH, por lo menos; tras el «punto de vista», ORTEGA de nuevo; tras la «justicia», TOMÁs DE AQUiNO o SuÁreZ; tras el «punto de vista sobre la justicia», otra vez ORTEGA y RECASÉNS, pero también KELSEN, y quizás LASK, MAYER y RADBRUCH; detrás de la «licitud y el deber» estaba KELSEN, al igual que tras el «sistema de legalidad», de la normatividad y el orden del Derecho; tras la «autarquía», ORTEGA, RECASÉNS o STAMMLER. Lo que llamaba la atención era el perspectivismo que adoptaba, pues si había varios puntos de vista, se entiende que igualmente legítimos, para constituir el Derecho, eso significaba que la concepción católica de la justicia no era la única o, si se quiere, que no habría un único Derecho natural sino tantos como posibles perspectivas. Creo, además, que la interpretación es acertada, y se demuestra a contrario sensu cuando más tarde LEGAZ mantuvo los términos, pero advirtiendo que no debían ser interpretados así (1979, p. 288 n.). Al menos en la guerra y en los primeros años tras ella, aunque el iusnaturalismo fuera mayoritario, no dejó de haber positivistas.

Curiosamente, frente a la filosofía mayoritaria, cualquier veleidad de innovación sería arrinconada en poco tiempo. No fue la potente especulación de ningún pensador sino el fin de la segunda guerra mundial y la derrota del fascismo las que elevaron definitivamente los pilares de la filosofía del Derecho y del Estado que se desarrolló bajo el franquismo: la afirmación de la catolicidad, el llamado humanismo y el Derecho natural, el repudio del comunismo y del totalitarismo en general, la defensa de la propiedad y de un orden social tradicional, así como la de una sui generis democracia sirvieron de cimientos del nuevo edificio. El momento daría lugar a una producción doctrinal de desigual valor. Basten dos ejemplos: mientras que en «Sentido español de 
la democracia», CORTS GRAU reivindicaba para el régimen franquista «las verdaderas esencias democráticas» (1946, p. 39); en «El Derecho natural y su incesante retorno» GALÁN realizaba una interesante clasificación de las doctrinas del Derecho natural a la vez que explicaba, precisamente, por qué éste retornaba siempre, y más en aquella hora (1945, p. 169).

\subsection{Autarquía y apertura: la estabilización de la filosofía jurídica (1945-1959)}

Así, a la altura de 1945 nos encontramos con que la academia universitaria de la Filosofía del Derecho ya se había estabilizado, no sólo en el sentido de que todas las plazas quedaran cubiertas y no se celebrara una nueva oposición hasta 1957, cuando obtenga la cátedra Agustín de Asís, sino en el de que el pensamiento católico triunfante se impondría por doquier. El panorama político internacional era novedoso, novedad que para España significó un aislamiento casi completo que sólo comenzará a levantarse a principios de los cincuenta y que irá superándose según avance esa década: concordato con la Santa Sede (1953), acuerdos con Estados Unidos (1953), entrada en la ONU (1955)... Probablemente también le convenga a esta etapa iusfilosófica el calificativo de autárquica: salvo la citada de Agustín de Asís no hay nuevas incorporaciones a la disciplina, tampoco existe - hasta donde sé- un contacto permanente con filósofos del Derecho extranjeros, escasean las traducciones de obras de filosofía jurídica... De nuevo eso no significa que durante este periodo no haya obras destacables; las hay, pero casi siempre orientadas en una misma dirección. Pienso en el magnífico libro de GÓMEZ ARBOLEYA sobre Francisco Suárez, S. I.; en la Introducción al estudio de la filosofía jurídica, de GALÁn, y la primera edición de su obra cumbre, el Ius Naturae; en los Fundamentos de Derecho natural, de TRUYOL... Como excepción, la orteguiana Introducción a los temas centrales de la Filosofía del Derecho, de LisSARRAGUE. Y la Filosofía del Derecho, de LEGAZ, reedición puesta al día y depurada de la hiperideologización de su Introducción a la ciencia jurídica, de 1943. Se trata de la primera edición del mayor tratado de filosofía jurídica escrito en España, en el que en cada nueva edición su autor incorporaba los últimos avances en la materia. No ha sido valorado como se merece.

Pero en esta academia casi siempre orientada en una misma dirección, la excepción fundamental, la nota discordante, la puso F. GonZÁLez ViCÉN. Como sabemos, tras complicadas peripecias, GONZÁLEZ VICÉN tuvo que huir de España durante la guerra civil. Luego volvería, creo que antes de que acabara la mundial, y tras ésta sería repuesto en la cátedra. En 1946, TRUYOL dejaba libre la plaza de La Laguna, con lo que el reingreso se produciría en la Universidad canaria, lo que parecía una solución satisfactoria para todos, pues es cierto que se lograba la vuelta del catedrático pero, a la vez, tratándose de un intelectual probablemente incómodo, mejor sería que estuviera alejado de los centros de poder. El curso 1947-48 dictaría la lección inaugural de la Universidad de La Laguna: La filosofía del Estado en Kant (1952), sin duda un tema impropio para la época. Después, en 1950, publicaría «El positivismo en la Filosofía del Derecho contemporánea», de nuevo un trabajo excepcional para el momento; excepcional no sólo por su calidad sino porque lo frecuente era historiar el Derecho natural, no el positivismo jurídico. Su orientación no era la dominante. Pero durante este periodo no publicó otros trabajos propios, sino que se dedicó básicamente a la traducción, sobre 
todo de obras históricas pero también, en la década de los cincuenta, pequeñas joyas del pensamiento jurídico: de Austin, de Kant, de Bachofen, de Welzel.

Otro de los acontecimientos que se produjo en el tiempo que duró esta etapa fue el fallecimiento de ORTEGA. El influjo que había ejercido en la Filosofía del Derecho española ya ha sido resaltado, pero será sobre todo a partir de ahora cuando se publiquen multitud de trabajos dedicados a exponer y, en su caso, criticar su pensamiento jurídico, algunos de enorme valor, hasta el día de hoy. ORTEGA, además, nos lleva a la cuestión del existencialismo, de moda en aquellos años también en nuestra filosofía jurídica. ¿Efectivamente existió un existencialismo jurídico en el panorama intelectual español de estos años, como decían LEGAZ y ELÍAS DE TEJADA? Ambos pretendían que en España, en aquel tiempo, había implantadas dos tendencias, una escolástica y otra existencialista (LEGAZ 1947, p. 355; ELÍAS DE TEJADA, 1949, p. 10), y el filósofo tradicionalista, además, que él representaba la conjunción de ambas. Semejante tesis, sin embargo, resulta discutible. Lo que sí había era orteguismo, raciovitalismo, y si el «raciovitalismo es un producto del horizonte intelectual en que se mueve toda la filosofía moderna, que es la existencia», como dijo LEGAZ (1947, pp. 342-343), entonces sí había existencialismo, las más de las veces diluido en una especulación de corte cristiano.

En esta etapa fallecerían (casi ágrafos) Pérez Blesa y CALLejo de LA Cuesta. También E. GÓMEZ ARBOLEYA, quien trágicamente puso fin a su vida en 1959, el mismo día que Eisenhower iniciaba su visita a España y tras haber abandonado la Filosofía del Derecho a cambio de la Sociología, abandono que también se produjo en los casos de S. LisSARRAgue (que se pasaría a la Filosofía social) y A. TRUYOL (que la cambiaría por el Derecho internacional). Precisamente el año en que el primero de éstos abandona la Filosofía del Derecho, 1953, tiene especial relevancia dentro de esta segunda época por dos motivos: por una parte porque es ese año cuando se implanta un nuevo plan de estudios para la licenciatura de Derecho (Derecho natural, en primer curso; Filosofía del Derecho, en quinto); por otra porque aparece entonces el Anuario de Filosofía del Derecho, especie de órgano de expresión de la iusfilosofía española. En ambos acontecimientos tuvo que ver J. RuIZ GimÉNEZ, que en ese momento ostentaba la cartera de Educación. De los filósofos del Derecho, fue quien más alto llegó en la jerarquía política: fue Presidente de Pax Romana entre 1939 y 1946; de este año a 1948, director del Instituto de Cultura Hispánica; luego, del cuarenta y ocho al cincuenta y uno, embajador cerca de la Santa Sede y, por fin, entre 1951 y 1956, ministro Educación. Sin duda su prestigio fue utilizado por el régimen para abrirse al exterior.

\subsection{Desarrollismo y tardofranquismo: el resquebrajamiento de la filosofía jurídica del franquismo (1959-1975)}

Si 1959 es un año clave para cualquier periodificación del franquismo, también lo es para la de la Filosofía del Derecho que se desarrolló durante ese régimen; no la fecha en sí sino el periodo que alrededor de ella se abre, que presenta muchas y fundamentales novedades. Por supuesto, se encuentra en él la continuación de lo que antes había pero también, enfrentadas al status quo, nuevas concepciones iusnaturalistas e, incluso, posturas positivistas y hasta marxistas. 
Ya a fines de los cincuenta, pero sobre todo en la década de los sesenta, dentro de la Iglesia Española comenzaron a oírse voces críticas frente al sistema político español, lo que traería consigo que hasta la doctrina del Derecho natural variara, encontrándonos ahora con un iusnaturalismo de raigambre católica y, sin embargo, opuesto al franquismo. En este sentido, el caso de RUIZ GIMÉNEZ resulta paradigmático, pues si había sido un buen representante del Derecho natural de posguerra y se había comprometido con el régimen, hasta el punto de ser embajador cerca de la Santa Sede y luego ministro, a estas alturas ya se encontraba distanciado tanto del franquismo como de una doctrina rígida del Derecho natural. Avanzados los cincuenta había advertido al régimen de que la legitimación religiosa de que gozaba no iba a ser eterna y ya en los sesenta abogará abiertamente por una opción democrática, que hallará su mejor tribuna precisamente en Cuadernos para el Diálogo, revista profética que anunciaba un próximo futuro en libertad. El objetivo de RuIZ GIMÉNEZ era, creo que sin duda, el de desvincular la doctrina iusnaturalista escolástica del sistema político español. No es extraño, por tanto, que sea un discípulo suyo, G. PECES-BARBA, quien en un futuro no muy lejano defienda una interesante y significativa tesis sobre el pensamiento de MARITAIN (1972), el más conocido intelectual católico antifranquista. En este apartado también habría que incluir a DíEZ AlEgRía y, en cierta medida, a ARANGUREN, entre otros menos conocidos.

Pero no todo era una oposición confesional (y iusnaturalista) al iusnaturalismo hasta ahora imperante, que se entendía como instancia legitimadora del franquismo, sino que el espectro se ampliaba y aparecían en el panorama español nuevos Derechos naturales. En cuanto al Derecho natural de corte existencialista, en las diversas versiones de HeIDEgGER, de SASTRE o de MAIHOFER, fue introducido sobre todo por L. GARCía SAN Miguel. En cuanto a la teoría de la naturaleza de la cosa, E. DíAz la recibió (junto con otros, sobre todo el penalista CEREzO MIR) a principios de los sesenta. Por fin, RodRíguez Paniagua remozaba el Derecho natural de la clásica filosofía cristiana con la nueva filosofía de los valores, a la vez que pedía que la polémica iusnaturalista permaneciera en el terreno filosófico, lo que parecía hacer referencia a las pugnas políticas que todavía la acompañaban. En efecto, las doctrinas del Derecho natural pagarán un alto precio por el uso ideológico que el franquismo hizo de éste, lo que hizo que algunos advirtieran contra el error (DELGAdo PinTO, 1982, 11; PÉREZ LuÑo, 1982).

Pero la transformación fue aún mayor. Por una parte, se observaba cierto interés por la metodología en algunas traducciones que fueron apareciendo aquellos años, aunque no las llevaran a cabo filósofos del Derecho: de Heck, de KANTOROwicz, de LARENZ. Por otra parte, surgían doctrinas anti-iusnaturalistas, a la vez que radicalmente enfrentadas con el status quo tanto iusfilosófico como político; me refiero al marxismo jurídico que, sobre todo, cultivará la escuela de Barcelona. M. SACRISTÁn, que con el tiempo alcanzará enorme prestigio, se dedicaba a la filosofía, no a la Filosofía del Derecho, pero escribirá un artículo sobre el pensamiento jurídico, «De la idealidad en el Derecho» (editado por primera vez en 1963, de este trabajo sólo se conserva un fragmento, reeditado en SACRISTÁN, 1984), un artículo en el que arremetía tanto contra el iusnaturalismo, que a su juicio no sólo era una más entre «otras varias modas medievalizantes», sino pura ideología, una ideología involutiva; como contra el positivismo, que aunque adoptara una posición «mucho más sólida y discreta», bajo capa 
de cientificidad ocultaba la misma «apología iusnaturalista del orden burgués». Frente a la idealidad del Derecho habría que observar su realidad, que no era otra — decía— que la del dominio de clase.

Ahora que ha aparecido M. SACRISTÁN hay que citar a su más significado discípulo, J. R. CAPELLA, un iusfilósofo que ya había innovado el panorama español al escribir el primer trabajo amplio sobre la filosofía del lenguaje aplicada al fenómeno jurídico (1968), quien publicaría un panfleto radical Sobre la extinción del Derecho y la supresión de los juristas (1970). En él, CAPELLA partía «del convencimiento de que todo Derecho es un mal», pues ni satisfacía las entonces actuales necesidades sociales ni era imparcial, y de que si bien habría que terminar con él, eso habría que hacerlo precisamente por medio del Derecho. En cuanto al Derecho natural, se trataba de una ideología del Derecho, «en el sentido de parcial o encubridora».

Se dijera o no abiertamente, por tanto, comenzaba a ser habitual que se viera en el iusnaturalismo hasta ahora imperante en España el recurso ideológico que el franquismo había utilizado para justificarse. En este sentido, los artículos que sobre el Derecho natural y la política publicaron E. DíAZ y L. GARCía SAN MigueL a principios de los sesenta resultaban esclarecedores, por más que para el primero los partidarios del Derecho natural, «en general», fueran de tendencia conservadora (1962, p. 74), mientras que para el segundo «no todo jusnaturalismo es necesariamente conservador y estático, que es posible un jusnaturalismo humanitario, progresivo» (1964, p. 37). A ellos se deberán, por cierto, poco más tarde, dos manuales innovadores en el panorama español: las Notas para una crítica de la razón jurídica, de GARCía SAN MiguEL (1969), y Sociología y Filosofía del Derecho, de E. Díaz (1971). Pero el Derecho natural no sólo se criticó por motivos políticos sino también por una cuestión de principio, porque se entendía que era más que dudoso que de veras existiese ese pretendido orden jurídico natural.

Creo que el capítulo más importante en la lucha de la época contra el Derecho natural lo constituyó la publicación de un libro que se convertiría en emblemático y que, curiosamente, se tituló Crítica del Derecho natural (VV.AA., 1966). Curiosamente - digo-, porque el original francés llevaba por título Le droit naturel a secas. Editado por Taurus, el responsable de la edición era E. Díaz, que había traducido todos los artículos que lo componían, a la vez que escrito el estudio preliminar bajo el título de «Introducción a la sociología del Derecho natural». En cuanto a los artículos que componían el libro, la mayoría de ellos no negaba el Derecho natural, pero sí los que constituían el grueso de la obra, el de KELSEN y el de BOBBIO. Realmente la unidad del libro colectivo no se hallaba en ninguna clave común a los pensamientos de los autores, sino que era otorgada por el lector, que podía ver en todos ellos la larvada crítica a la que se consideraba ideología jurídica del régimen, con lo que Crítica del Derecho natural se convertía en Crítica del Derecho natural del franquismo. También hay que referirse aquí a otra obra de E. DíAz de aquellos años, Estado de Derecho y sociedad democrática, que se convertiría en un clásico. En síntesis, mantenía que más que de Estado de Derecho habría que hablar de Estados de Derecho, pues al Estado liberal de Derecho, propio del siglo XIX, le había seguido el Estado social, típico de las sociedades del bienestar, y en un futuro probablemente se alcanzara otro Estado democrático de Derecho, superador de las contradicciones de los anteriores. En fin, 
aunque no se mencionara a España, quedaba claro que el Estado franquista no era ni un Estado de Derecho ni otro democrático. Como comienza a observarse, E. DíAz se estaba convirtiendo en un nuevo motor de la Filosofía del Derecho española, jugando un papel similar al que jugó RECASÉnS en tiempos de la dictadura de Primo de Rivera. La referencia a su trabajo vale también para constatar la implantación, avanzados los sesenta y hasta nuestros días, de una nueva temática en la filosofía jurídica española, la de los derechos humanos (vid. GARCía MANRIQUe, 1996). La dedicación a la temática no sólo era un ejercicio doctrinal, sino también la expresión de una opción política crítica con un régimen que los conculcaba. Precisamente la escuela en la que se integraba E. DÍAZ, la de RuIZ GIMÉNEZ, será la que se dedique más intensamente a introducir esa temática. El mismo RuIZ GiméNEZ publica aquellos años una obra muy representativa del momento de la Iglesia: El Concilio Vaticano II y los derechos del hombre (1968), y G. PECES-BARBA ya en 1973 publica la primera edición de sus Derechos Fundamentales, «elemento indispensable de una sociedad democrática», advertía (1973, p. 12), y cuya doctrina va a ser desarrollada por una amplia escuela hasta el día de hoy.

Pero volviendo a lo que antes me refería, al reproche que se lanzó contra la ideología jurídica del franquismo, aún faltaba otra crítica rotunda contra el Derecho natural; me refiero a la tesis censoria de F. GONZÁLEZ VICÉN (1969), que pretendería nada menos que negar carácter iusfilosófico a las doctrinas del Derecho natural. En síntesis, vino a decir que los conceptos podían ser históricos o formales: históricos cuando se vinculaban necesariamente a una «estructura histórica» determinada, de tal forma que no podrían aplicarse con sentido a momentos históricos distintos (por ejemplo, el concepto de polis); formales, en cambio, cuando no sufrían esa dependencia y se utilizaban indistintamente para referirse a una realidad, ya se diera en uno u otro momento de la historia (por ejemplo, el concepto de conjunto). Pues bien, el concepto de filosofía del Derecho sería, según GONZÁLEZ VICÉN, histórico, pues estaría vinculado a una estructura histórica determinada; habría nacido a fines del XVIII, comienzos del XIX, precisamente cuando comienza a arrumbarse la vieja denominación de Derecho natural. No se decía, pero de esa conclusión era fácil seguir otra: quienes en España se dedicaban al Derecho natural, casi todos los compañeros de GonZÁLEZ VICÉN, no eran verdaderos filósofos del Derecho, sino meros iusnaturalistas. La tesis generó algunas críticas, aunque larvadas, sin que se abriera una discusión pública. A mi juicio, sin embargo, tenía fácil respuesta. La que fallaba era la clasificación de los conceptos que hacía GONZÁLEZ VICÉN, pues si bien algunos son efectivamente históricos y otros realmente formales, la mayoría de ellos pueden ser tanto históricos como formales, dependiendo de cómo se usen en cada caso. Resultaba así que si F. GonZÁLEZ afirmaba que era el de filosofía del Derecho un concepto histórico, también podría decirse que era formal y argumentarlo con sus propias palabras (RIVAYA, 1998c, p. 41).

Esa referencia a los compañeros de GONZÁLEZ ViCÉN hace que se tenga que apuntar ahora quiénes accedieron a las cátedras durante este periodo. En 1960 la lograron J. Delgado Pinto, que jugará un papel especialmente relevante en la disciplina, y M. HurTado Bautista; en 1966, F. PuY y N. M. a LóPez CAlera, y casi coincidiendo con el final de la dictadura, en 1974, J. J. GiL CREMADES y E. DíAz, quien desde al año anterior dirigía una novedosa revista, Sistema, que resistirá el paso del tiempo. De distinta línea ideológica, en 1974 también comenzará a editarse otra revista, ésta vinculada a la 
Universidad de Navarra, que será longeva, llegando hasta el día de hoy, Persona y Derecho. Pero lo que importa ahora es la cuestión del acceso a las cátedras. Si sobre todo había sido M. Puigdollers quien, desde el fin de la contienda civil, había controlado ese acceso a las de Filosofía del Derecho, avanzados los sesenta esa labor la asumió F. ELÍAS DE TEJADA, que creó una situación absolutamente anómala y preocupante que con razón ha sido llamada de «terror intelectual» (GIL CREMADES, 1985, p. 233). En concreto, tanto a Gil CREMADES como a E. DíAz les había vedado el acceso y ahora, como antes se había roto el monopolio doctrinal, se quebraba aquel control y los dos lograban la cátedra. Todavía seguiría habiendo escaramuzas a la hora de decidir la distribución de plazas, pero inevitablemente la filosofía del Derecho se abría a un tiempo nuevo y a nuevas perspectivas.

\section{DEMOCRACIA Y FILOSOFÍA DEL DERECHO (1975-2000)}

Por su cercanía, resulta difícil escribir la historia de la filosofía jurídica del último cuarto del siglo XX. Si seguimos utilizando la periodificación ordinaria de la historia política, no cabe duda que es más sencillo narrar lo que ocurrió durante el periodo de la transición que lo que ocurrió después, pues se acepta generalmente que la transición dura hasta 1982, cuando por primera vez llegó el PSOE al poder, mientras que lo que ocurrió después llega hasta nuestros días o, si se prefiere, está ocurriendo, es presente.

\subsection{Transición y filosofía del Derecho (1975-1982)}

Al igual que en lo político, también hubo una transición iusfilosófica, cuyo primer tramo vino constituido, en el ámbito académico, por la oposición citada, en la que obtuvieron plaza GIL CREMADES y E. DíAz. Obvio es decir que durante este tiempo, alrededor de 1975, en la disciplina el ambiente estaba enrarecido. Probablemente porque dedicarse a la Filosofía del Derecho también era hacer política. Algunos iusfilósofos que habían comenzado su labor en los años sesenta ya lo sabían: por ejemplo E. DíAz, que fue desterrado a Villagordo (Jaén), y G. PECES-BARBA, que fue confinado en Santa María del Campo (Burgos), ambos en 1969, cuando se declaró el estado de excepción. Después, inminente el fin del franquismo, otro filósofo del Derecho, M. ATIENZA, acusado de un delito de propaganda ilegal (había pronunciado una conferencia sobre derechos humanos), tuvo que marcharse a Argentina.

En aquel ambiente enrarecido, sin embargo, también se produjeron sucesos doctrinales relevantes que no se pueden obviar en esta historia. Del año que inevitablemente marca la frontera entre el antes y el después, 1975, hay que referirse al número monográfico de los Anales de la Cátedra Francisco Suárez que se tituló La Filosofía del Derecho en España, que constituyó el intento colectivo más serio de dilucidar lo que era y/o debía ser la Filosofía del Derecho. Que la obra apareciera cuando lo hizo trajo consigo que algunos autores apuntasen el cambio que se vislumbraba en nuestra Filosofía del Derecho, y también en su concepto. Es cosa sabida que la que se había elaborado durante el franquismo (en rigor, una parte importante, no toda) tenía un carácter apologético de un estado de cosas inadmisible. Era la demostración — decía ATIENZA- 
de que algunas filosofías jurídicas no pasaban de ser simples ideologías, utilizado el término en su sentido más despectivo, lo que explicaría el casi nulo avance que esta disciplina habría experimentado en España durante los últimos tiempos, en opinión de PeCES-BARBA. Tampoco era extraño, dado que otros aseguraban con buen juicio que todos los juristas eran políticos (Ollero), lo que incluiría también a los iusfilósofos. Que esta especulación, más o menos abiertamente, hubiera sido política, por tanto, no sería criticable, y sí lo sería en cambio su orientación. Frente a aquélla se oponía ahora otra que aún no estaba hecha: «me parece absolutamente urgente — decía M. ATIENZA— emprender una tarea de renovación que tal vez haya empezado ya».

En esta obra colectiva, por lo demás, se acuñaron dos tópicos que aún hoy siguen implantados en nuestra filosofía jurídica: el del carácter crítico que tiene/debe tener ésta y el de su tripartición temática. De una u otra tendencia, casi todos dijeron que la función de la filosofía jurídica era criticar (vid. RIVAYA, 2006). Quizás fueron LAPORTA, HIERRO y ZAPATERO quienes más incidieron en la cuestión, a la vez que apuntaron que de ahí se seguía la necesidad de elaborar una teoría de los valores. Lo había dicho también GIL CREMADES de forma meridianamente clara, que la crítica «es imposible si no se parte de unos criterios», y habría que elaborarlos. Esos valores o criterios bien podrían ser los del Derecho natural, pero éste arrastraba una mácula: la dictadura había gozado de una legitimación iusnaturalista, lo que hizo que muchos no sólo no lo considerasen sino que lo condenasen sin paliativos. La otra cuestión que generó consenso fue la de los temas de la Filosofía del Derecho: con unos u otros nombres, casi todos reconocieron que la ontología, la gnoseología y la axiología jurídicas constituían los reinos de la filosofía jurídica. Tras leer aquel número de los Anales quedaba la sensación de que se abría un horizonte esperanzador, cuando por todos se reconocía que la Filosofía del Derecho tenía sentido (no sólo existía sino que debía existir) y una importante función que cumplir. Tal vez no fuera la principal, pero también era necesaria la de participar en la formación de los juristas, aseguraba DELGADO PINTO.

Acabamos de citar a jóvenes filósofos del Derecho, representantes de una nueva generación. Este dato es importante porque para comprender la transición a una nueva filosofía del Derecho no sólo se debe tener en cuenta el cambio de coordenadas políticas sino también la desaparición de una generación de pensadores dedicados a la disciplina, algunos de los cuales tenían una importancia fundamental. Me referiré otra vez al caso de LEGAZ pues antes de morir tuvo tiempo para llamar a la moderación y prestar su apoyo a la transición. Por muchas razones, el artículo que tituló «La lealtad política», que tuvo que escribir poquísimo después de morir Franco, tiene una importancia extraordinaria, así como claves que se ofrecían al final de una vida. Por supuesto, no trató de justificarse; incluso reconoció su lealtad al Caudillo, pero lo que ahora importa es que justificó la transición que ya adivinaba (1976, p. 27 y n.). En la transición, por cierto, la Filosofía del Derecho tuvo algún protagonismo. Es cierto que muchos miraron el proceso con la distancia de los años, pero también hubo quien se comprometió prácticamente con el cambio: RuIZ GIMÉNEZ dirigiendo un proyecto demócrata-cristiano que fracasaría; G. PECES-BARBA obteniendo escaño en la lista del PSOE por Valladolid; Agustín de Asís presentándose al Senado por Alianza Popular. Pero no sólo colaboraba con el cambio quien hacía política activa, sino que desde diversos ámbitos se podía participar, como demostraron con sus artículos de prensa 
N. M. a López Calera (1992), E. Díaz (1987) y L. García San Miguel (1998), entre otros. En poco tiempo habría hasta una teoría de la transición hecha por un filósofo del Derecho (GARCía SAN Miguel, 1981), así como una crítica sistematizada de muchas de las teorías de la transición, hecha por otro iusfilósofo (DíAZ, 1989).

La meta del tránsito fue el acontecimiento más importante de toda la cultura jurídica española del siglo Xx: la Constitución de 1978. Resultado de la andadura política de los tres años posteriores a la muerte de Franco, con la Constitución de 1978 España se constituía, por fin, conforme al artículo uno y a E. DíAz, en un «Estado social y democrático de Derecho». Como se sabe, uno de los miembros de la Comisión Constitucional que cumplió el encargo de elaborar un texto constitucional fue G. PECES-BARBA, en representación del grupo parlamentario socialista y, podríamos decir, de la filosofía jurídica. Por lo que a los influjos filosóficos de la Constitución se refiere, el hecho de que fuera PECES-BARBA miembro de la Comisión creadora del proyecto hace que haya quien vea en ella el pensamiento de MARITAIN (Tusell, 1985, p. 16), aunque eso no signifique ni mucho menos que PECES-BARBA representara una corriente confesional o algo por el estilo. La orientación ideológica del filósofo del Derecho que actuó de ponente, así como su especialización en el ámbito de los derechos humanos, tuvieron que influir, por un lado, en el carácter plural de la Constitución, pero también en la inclusión de una línea socialdemócrata, y por otro en la arquitectura del edificio de los derechos fundamentales. La Constitución trajo consigo el cambio político y con él una nueva cultura jurídica, un nuevo paradigma que hacía que las cosas jurídicas tuvieran que pensarse de nuevo y desde nuevas perspectivas. Sin duda lo más importante fue la consolidación de una temática que ya había comenzado a desarrollarse en España en la década de los sesenta, si bien de forma problemática, la de los derechos humanos. Era natural que la nueva situación constitucional trajera el florecimiento de una doctrina iushumanista, como así fue.

Pero ahora querría referirme a otra cuestión que, curiosamente, también tuvo que ver con la nueva Constitución, la del influjo del marxismo en la cultura jurídica española, que no fue menor. La cuestión es que la nueva norma fundamental valió como argumento para una corriente del pensamiento jurídico de raigambre marxista (aunque desbordara los estrechos marcos del marxismo jurídico clásico), de influjo gramsciano, que importada de Italia obtendría predicamento en la España de aquellos años, el uso alternativo del Derecho. Realmente en España «el nacimiento del movimiento del uso alternativo estuvo íntimamente ligado a los últimos años del régimen franquista, como una forma de resistencia a éste, aunque sus posibilidades efectivas se dieron en el periodo inmediatamente posterior, en la transición democrática» (SOUZA, 2001, p. 107). En la recepción del uso alternativo participaron, cómo no, magistrados: sobre todo Plácido Fernández Viagas y Perfecto Andrés Ibáñez, quizás el jurista más representativo de la corriente en España. También intelectuales marxistas que a la vez eran dirigentes del Partido Comunista, como José María Laso. En los ámbitos de la filosofía académica del Derecho creo que fue el departamento de Filosofía del Derecho de la Universidad de Granada, bajo la dirección de N. M. . LÓPEZ CALERA, el centro de recepción y desarrollo del uso alternativo del Derecho en España.

Pero el marxismo también estuvo presente en una polémica cuyo origen se encuentra en un artículo que se publicó al año siguiente de haberse promulgado la nueva 
Constitución; otra vez un artículo de GONZÁLEZ ViCÉN, que se tituló «La obediencia al Derecho», y al que le cabe el indiscutible mérito de haber sido el más discutido de la historia de la Filosofía del Derecho española del siglo XX. A primera vista no parece extraño su carácter polémico, dada la tesis que defiende: «mientras que no hay un fundamento ético para la obediencia al Derecho, sí hay un fundamento ético absoluto para su desobediencia». En los años siguientes se produjo una cascada de críticas. Evidentemente, se podía o no estar de acuerdo con la subversiva tesis de GONZÁLEZ VICÉN, pero gran parte de la confusión que se creó fue debida al hecho de que quienes la discutieron partían de premisas distintas a las de aquél: una de raigambre existencialista, que solamente la conciencia ética individual es capaz de generar obligaciones; y otra de signo marxista, que el Derecho es un instrumento que una clase social utiliza para someter a otra.

Al hilo de estas referencias a esas ideas marxistas, creo que hay que decir, que se puede decir, que en los últimos años del régimen de Franco y los primeros de la democracia el marxismo se convirtió en una moda, moda que se implantó también en la Filosofía del Derecho. Visto desde aquí, resulta normal: tras muchos años de silencio, de «condena apriorística» y de «un desprecio que niega al pensamiento de MARX dignidad y altura de auténtica filosofía» (1983, p. 101), poco a poco, en los años sesenta, comenzó a recuperarse el pensamiento marxista y en los setenta y ochenta todos los intelectuales habían leído lo fundamental de la obra de MARX, también los que se dedicaban a la filosofía jurídica. El reconocimiento de la implantación del marxismo en la filosofía española, también en la del Derecho, no significa ninguna condena del materialismo jurídico sino, simplemente, una constatación de que existió un gran interés por él y que muchos intelectuales, entre ellos algunos filósofos del Derecho, se tuvieron por marxistas o se vieron influidos por el marxismo. Hubo bastantes lecturas marxistas de doctrinas jurídicas. Por citar tan sólo dos tesis doctorales cuyos autores siguieron luego trayectorias distintas, me parece que tanto la de G. ROBLES, una lectura de ORTEGA, como la de A. CALSAMIGLIA (por desgracia, prematuramente desaparecido), una lectura de KELSEN, mostraban a las claras influjos marxistas. También hubo traducciones: de CerRoni, de Pashukanis, de StOyanovitch, de PoulantZas, entre otros. Por fin, aparecieron estudios sobre la ideología de MARX aplicada al Derecho, como los de E. Díaz, V. Zapatero, C. Eymar, M. Calvo, N. López Calera, M. Atienza y J. Ruiz MANERo. A los dos últimos citados se debe un trabajo de relectura crítica, Marxismo y Filosofía del Derecho (1993), que puede tenerse por el fin de la moda, pero también por el punto seguido para un pensamiento que, si no se convierte en dogmático, puede y debe seguir cumpliendo, en un contexto iusfilosófico plural, un papel crítico. En cualquier caso, el declinar del marxismo es, visto desde aquí, un síntoma del fin de la transición; también del fin de la transición iusfilosófica. Tanto España como la Filosofía del Derecho española dejaban de ser diferentes.

\subsection{La filosofía del Derecho en democracia (1982-2000)}

Esta última etapa, ya está dicho, no es pasado sino presente. De hecho, no creo que se encuentre ninguna censura importante desde 1982 hasta hoy, sino evolución que ha llevado a la Filosofía del Derecho española a ocupar un estimable nivel en el contexto 
europeo que le es natural. Señalaremos algunos hitos, los que creo más importantes, de este presente, pero antes comencemos por apuntar las características de este periodo que, frente a las de los anteriores, le otorgan su particular fisonomía.

En primer lugar, la recuperación de la normalidad política creó un ambiente en el que también se normalizó la Filosofía del Derecho española, sobre todo porque se integró en su geografía, en el mapa europeo.

En segundo lugar, el importante aumento del número de personas que se dedican profesionalmente a la filosofía del Derecho, de profesores de Filosofía del Derecho (y de profesoras, que la incorporación de la mujer ha sido otra novedad también en la academia filosófico jurídica), debido sin duda a la proliferación de Facultades de Derecho, en el marco de una expansión universitaria como nunca existió en la historia de nuestra Universidad.

En tercer lugar, vinculado al dato anterior, la producción iusfilosófica española irá aumentando hasta alcanzar una situación de abundancia (y habrá quien diga sobreabundancia) frente a la escasez bibliográfica de la que hablaba LEGAZ a principios de los años treinta.

En cuarto lugar, el giro anglosajón que se observa en la nueva filosofía jurídica que se reclamaba y que se implanta en la España de la democracia. No es que haya desaparecido el influjo germánico, que sigue existiendo, pero la ascendencia hoy fundamental - creo- le corresponde a la que se escribe en lengua inglesa.

En quinto lugar, la circunstancia política, ya normalizada, ha traído consigo -me parece- que disminuyera la tendencia crítica de la Filosofía del Derecho a cambio de otra más analítica que adopta el punto de vista interno de un ordenamiento democrático.

Si el nuevo periodo se abre en 1982, con la llegada del PSOE al poder, otra vez hay que apuntar la coincidencia: ese mismo año, en unas famosas oposiciones, obtuvieron plazas de agregado nada menos que cinco profesores: A. OlLERO, J. R. CAPELLA, G. Peces-Barba, M. Rodríguez Molinero y L. García SAn Miguel. Llama la atención el pluralismo del grupo, las variadas tendencias filosóficas y políticas que en él se encontraban. Al igual que el panorama político general se normalizaba, hasta el punto de que, sin que quebrara el sistema, los socialistas formaban gobierno; la Filosofía del Derecho también comenzaba a gozar de una normalidad que permitía, por ejemplo y sobre todo, ese pluralismo ideológico del que hablo, pluralismo que en absoluto había sido habitual a lo largo del siglo que avanzaba ya hacia su término.

En perspectiva institucional, la nueva etapa ha traído consigo órganos de difusión que, sin duda, eran necesarios. En 1984 reaparece el Anuario de Filosofía del Derecho, ahora dirigido por J. J. GIL CREMADES, tarea que desempeñará hasta 1996, cuando le sustituya J. DE LUCAS en la dirección. También en 1984 aparecerá una nueva revista en el panorama iusfilosófico español, Doxa, Cuadernos de Filosofía del Derecho, publicada en la Universidad de Alicante y dirigida por M. ATIENZA, con un formato que incluye la recopilación bibliográfica de lo editado sobre Filosofía del Derecho en español y el género de la entrevista. En la década siguiente surgirá el Instituto de Derechos $\mathrm{Hu}$ manos Bartolomé de las Casas, que editará una nueva revista, Derechos y Libertades, dirigida por PECES-BARBA. Junto con las ya existentes, las nuevas publicaciones sirven 
para mostrar la nueva situación y —creo- el vigor de la Filosofía del Derecho española, integrada por fin en el contexto iusfilosófico europeo. También desde el punto de vista institucional es necesario fijarse, por lo que toca a la Filosofía del Derecho, en el nuevo plan de estudios jurídicos de la democracia. En 1990 se dictó un decreto que estableció un nuevo plan de estudios para la licenciatura de Derecho, modificando el que estuvo establecido durante casi cuarenta años. En primer curso, en sustitución del Derecho natural, se estableció la asignatura titulada Teoría del Derecho, mientras que se mantuvo en quinto curso la de Filosofía del Derecho. Conforme a la legítima demanda de muchos iusfilósofos, los encargados de estas asignaturas, se removía el rótulo de Derecho natural, vinculado a una opción ideológico jurídica concreta. Otro cambio importante fue que a las nuevas asignaturas se les redujo la carga docente.

Pero hay que pararse, obviamente, en una producción doctrinal muy amplia que, precisamente por su amplitud, necesita ser ordenada. Para una primera aproximación, quizás pueda valer la tripartición temática ya referida y habitualmente aceptada de la Filosofía del Derecho, que distingue entre el concepto del Derecho, la metodología jurídica y la teoría de la justicia, aunque haya que advertir desde un principio que la clasificación es insuficiente, sobre todo porque las tres ramas iusfilosóficas se encuentran inevitablemente entrelazadas. En cualquier caso, si comenzamos por la cuestión del concepto del Derecho, conviene referirse a los muchos estudios que aparecieron en esta última etapa sobre los filósofos del Derecho que mundialmente se consideraban más importantes: KELSEN, ROSS y HART.

KELSEN ya había fallecido, pero continuó siendo estudiado como el clásico que era. Quizás no hubo quien defendiera una concepción kelseniana del Derecho en la academia iusfilosófica, pero la teoría pura fue tenida en cuenta por los filósofos del Derecho. Siguió, habría que decir, porque realmente nunca había dejado de ser tenida en cuenta, por más que, en su momento, los que se tenían por la ortodoxia del franquismo lo repudiaran. Ahora continuó el estudio pero me parece que adquirió forma distinta; se redujeron los análisis generales, aunque siguió habiéndolos, y aumentaron los que se fijaban en concretos aspectos: la derogación, la lógica deóntica, la ciencia jurídica, el principio de jerarquía normativa o el papel de la eficacia en la validez del Derecho, entre otros; todos en el marco de la teoría pura. Pero también aparecieron estudios sobre la clave de bóveda de la construcción kelseniana, la norma fundamental. En cuanto a Ross y a la corriente realista en la que se integraba, en España hay especialistas en ese pensamiento y, más o menos por estos años, se publicó algún trabajo fundamental sobre el mismo. Creo que las corrientes realistas, sin embargo, han sido poco seguidas aquí. Mucho más entusiasta sería el recibimiento (incluso físico, personal) del tercero de los grandes que he citado, H. L. A. HART. Sobre su doctrina se leyeron importantes tesis doctorales, se publicaron bastantes estudios (hasta se le entrevistó para una revista española) y se tradujeron algunos de sus trabajos, aunque la versión castellana de su obra máxima, El concepto de Derecho, apareció en Buenos Aires. Pero antes de continuar por la senda de DWORKIN y la crítica a HART, hay que advertir que el filósofo más traducido y glosado en la España de la democracia no fue ninguno de esa trinidad sino otro grande de la filosofía europea que ha tenido en España una importancia formidable, N. Bоввіо. Hay que tener en cuenta dos datos que le han convertido en imprescindible. Por una parte el carácter enciclopédico de su obra, que hizo que fuera tenido en 
cuenta en multitud de discursos; por otra, la virtud de la mesura de su reflexión, quizás demasiado ecléctica a veces, que inspira a quienes se han nutrido de sus fuentes. Son tantas las traducciones de obras de BOBBIO y los estudios sobre su filosofía jurídica y política que resultaría difícil citar todos. En cuanto a los críticos de HART, que en cierta medida han señalado el camino de la filosofía del Derecho posterior, hasta hoy, sobre todo va a destacar DwORKIN, de quien aquí ha habido pronta noticia y traducción, el que quizás va a convertirse en el teórico del Derecho más influyente. De nuevo, sería muy difícil hacer un listado completo de sus estudiosos españoles. La novedad de tesis como la de los principios, que afirma que el Derecho no sólo es un conjunto de reglas, que también contiene principios, o la de los derechos, que se entienden como triunfos frente a las pretensiones mayoritarias, abren la puerta a ulteriores desarrollos que nos hacen ver el Derecho no tanto como un producto acabado cuanto como un realidad siempre en construcción. Probablemente ésa sea la gran diferencia entre las concepciones de principios de siglo y la de finales. Realmente en la centuria hay - creo- tres tendencias: mientras que antes (y aún hoy) el Derecho era visto, entendido, como un objeto encontrado en el mundo o construido, pero en cualquier caso acabado, que podía ser descrito como cualquier otra realidad, luego pasó a ser concebido como un punto de vista, una perspectiva (aunque HART la popularizó, la idea es clásica en el pensamiento jurídico y tiene en el español el referente básico del perspectivismo de ORTEGA, que desarrolló RECASÉNS en la filosofía del Derecho y que encuentra su mejor aplicación en la definición de Derecho de LEGAZ, que precisamente comienza diciendo que el Derecho es un punto de vista), una perspectiva — decía - que convertía en Derecho aquello que observaba; ahora el fenómeno jurídico se asemeja más a la actividad que se realiza con algún material maleable, que puede tomar diversas formas y dar lugar a resultados diversos (aunque curiosamente DWORKIN mantenga la tesis de la única respuesta correcta). Objeto, perspectiva y praxis puede ser criterios de clasificación de las concepciones del Derecho que se desarrollaron a lo largo del anterior siglo.

En cierta medida, el principialismo se va a convertir en un camino por el que transitarán otros muchos autores que también serían bien recibidos en España, donde encontrarán seguidores: con un discurso de raigambre habermasiana, R. ALEXY; proveniente del iusalternativismo y ahora representante del garantismo, L. FERRAJOLI; desde el Derecho Constitucional, G. ZAGREBELSKY, que con El Derecho dúctil provocaría una gran polémica en España; del ámbito anglosajón, J. RAZ y N. MACCORMICK; todos ellos convenientemente traducidos, a veces en España y a veces en Latinoamérica, y estudiados. La nueva dirección hizo que comenzara a hablarse de postpositivismo; también que hubiera quien se preguntara en alta voz si la eterna dialéctica entre el positivismo y el iusnaturalismo no había quedado agotada o, en todo caso, si no debería superarse cuanto antes. Sin embargo, la secular tradición de la dialéctica iusnaturalismo/positivismo, así como su utilidad para clasificar en dos todo el campo del pensamiento jurídico, hace que nos preguntemos por la conveniencia de su desaparición. Por cierto, si toda ideología jurídica o es iusnaturalista o es iuspositivista, el postpositivismo es iusnaturalismo. En cualquier caso ese principialismo neoconstitucionalista también ha encontrado adversarios que, ante tanta posible discrecionalidad, reivindican el imperio de la ley. En ésas estamos.

Si esa línea evolutiva versaba fundamentalmente sobre el concepto del Derecho, es evidente que de éste depende la metodología que se adopte, y la cuestión metodológica 
consigue en esta época un creciente interés. Si hay un giro en las fuentes, ahora más anglosajonas, también hay un giro en la orientación de la especulación, ahora más metodológica. Frente a quienes creían en algún procedimiento para dotar de racionalidad a las decisiones jurídicas estaban los escépticos que, al contrario, veían inevitables subjetivismos, cuando no inconfesables intereses o motivaciones, en el acto de decidir. Entonces surgirían las teorías de la argumentación, de la mano de PERELMAN y VIEHWEG, que estarían llamadas a jugar un importante papel en la teoría y la metodología jurídicas del presente, tanto europeas en general como españolas en particular. Si el Derecho consiste en argumentar se trata de saber cómo tiene que ser ese razonamiento para que la decisión jurídica esté fundamentada, para que el resultado sea razonable. Esa palabra, razonable, que ya había utilizado RECASÉNS, se convirtió en el fin del Derecho. Aunque menor, el otro capítulo metodológico correspondería a la hermenéutica, que despertó el interés de los filósofos del Derecho ante la posibilidad de aplicarla al mundo jurídico. En este apartado metodológico también hay que referirse al interés que suscitó el estudio de los hechos en sede jurídica. Evidentemente, el jurista no sólo ha de conocer las normas a aplicar sino también los hechos sobre los que han de ser aplicadas, y muchas veces se ha olvidado que este cometido también lo lleva a cabo el jurista.

Por fin, en cuanto a la teoría de la justicia, el imperio de los derechos humanos resulta evidente, imperio que la Constitución refrendó, como ya quedó apuntado. Casi ningún filósofo del Derecho español ha dejado de escribir de los derechos humanos, en cierta medida — se ha dicho, creo que con razón— herederos del Derecho natural. En este marco hay libros y artículos que ya se pueden tener por clásicos, tanto referidos a la teoría general de los derechos humanos como al estudio de concretos derechos. El tema de la fundamentación ha traído consigo una abundante y controvertida literatura donde se han dado cita desde las necesidades hasta la argumentación, desde los grandes ideales hasta los datos objetivos y los diálogos intersubjetivos. En este capítulo habría que hacer referencia a la tendencia política de la filosofía jurídica, que la convierte en filosofía política claramente, y destacar sobre todo el estudio de la obra de J. RAWLS, al que se dedicaron varias tesis doctorales, así como el de temas fundamentales vinculados a los derechos humanos: el del liberalismo, el del valor de la tolerancia, el del multiculturalismo, etc. No han dejado de estudiarse, por supuesto, las críticas a los derechos humanos, tanto las clásicas como las más modernas.

Evidentemente, el panorama no ha quedado suficientemente descrito. Hay otras cuestiones, a veces genéricas, a veces más específicas; en cualquier caso, hay que apuntar los temas de nuestro tiempo, de los que también se han ocupado los filósofos del Derecho: desde la inmigración y el multiculturalismo, la globalización o el influjo de la postmodernidad en el Derecho, hasta el nacionalismo o la bioética, dentro de la que aparecen temas clásicos, como el de la eutanasia, por la que ha habido un enorme interés bibliográfico, o el del aborto. También habría que hacer referencia a la recepción de otros movimientos, de los que al menos se da cuenta: análisis económico del Derecho, jurisprudencia feminista, Critical Legal Studies. Hay además otros estudios que utilizan perspectivas más o menos novedosas. Desde la clásica de la historia del pensamiento jurídico, de la que se han ocupado casi todos los actuales filósofos del Derecho, hasta la menos transitada de la lógica deóntica, la informática jurídica, o los estudios culturales del Derecho, sobre todo los de Literatura y Derecho. 
Aunque no haya que echar las campanas al vuelo, si ahora se mira para atrás, al final, cuando ya se abre una centuria nueva y a la vez se cierra el convulso siglo XX español, convulsión que dio cierto carácter anómalo a la Filosofía del Derecho que se hizo aquí durante buena parte del mismo, si se mira para atrás — digo— creo que hay razones para el optimismo.

\section{BIBLIOGRAFÍA}

ALAS, L., 1878: El Derecho y la moralidad. Determinación del concepto del Derecho, y sus relaciones con el de la moralidad, Madrid, Medina.

Álvaro DueÑas, M., 1999: «El decoro de nuestro aire de familia». Perfil político e ideológico de los Presidentes del Tribunal Nacional de Responsabilidades Políticas. Revista de Estudios Políticos, núm. 105, pp. 147-173.

- 2006: «Por ministerio de la ley y voluntad del Caudillo». La Jurisdicción Especial de Responsabilidades Políticas (1939-1945), Madrid, Centro de Estudios Políticos y Constitucionales.

ArRARÁs, J., 1969: Historia de la segunda República española, Madrid, Editora Nacional, vol. 2. Atienza, M., y Ruiz Manero, J., 1993: Marxismo y Filosofía del Derecho, México: Fontamara.

CAPELLA, J. R., 1968: El Derecho como lenguaje. Un análisis lógico, Barcelona, Ariel.

- 1970: Sobre la extinción del Derecho y la supresión de los juristas (consideraciones oblicuas), Barcelona, Fontanella.

CORTS GRAU, J., 1934: «Georges Renard y su doctrina de la institución», Revista de Derecho Público, núm. 28, pp. 97-108.

- 1946: «Sentido español de la democracia», Revista de Estudios Políticos, núms. 25-26, pp. 1-41.

Del Vecchio, G., 1908: Los supuestos filosóficos de la noción de Derecho, Madrid, Sucesores de M. Minuesa de los Ríos.

- 1923: Conferencias pronunciadas en los días 9, 10, 12 y 14 de abril de 1923, en el Salón de Grados de la Facultad de Derecho, por Giorgio del Vecchio, Madrid, Publicaciones de la Universidad de Madrid.

Delgado Pinto, J., 1982: De nuevo sobre el problema del Derecho natural, Salamanca, Ediciones de la Universidad de Salamanca.

DíAz, E., 1962: «Sentido político del yusnaturalismo», Revista de Estudios Políticos, núm. 124, pp. 65-80.

- 1966: Estado de Derecho y sociedad democrática, Madrid, Cuadernos para el Diálogo.

- 1971: Sociología y Filosofía del Derecho, Madrid, Taurus.

- 1973: La filosofía social del krausismo español, Madrid. Edicusa.

- 1983: Pensamiento español en la era de Franco (1939-1975), Madrid, Tecnos.

- 1987: La transición a la democracia (Claves ideológicas, 1976-1986), Madrid, Eudema.

- 1989: «La ideología de (sobre) la transición», en J. F. Tezanos, R. Cotarelo y A. DE BLAS, La transición democrática española, Madrid, Sistema.

ElíAs DE TEJADA, F., 1949: «Panorama de la Filosofía del Derecho en la España actual», Revista General de Legislación y Jurisprudencia, núm. XVIII, pp. 10-36.

Galán GutiÉRreZ, E., 1942: «La Filosofía del Derecho de Emil Lask en relación con el pensamiento contemporáneo y con el clásico», Revista General de Legislación y Jurisprudencia, núms. 2 y 4, pp. 123-162 y 361-412. 
- 1945: «El Derecho natural y su incesante retorno», Revista Crítica de Derecho Inmobiliario, núm. 202, pp. 168-177.

García MANRiQue, R., 1996: La filosofía de los derechos bumanos durante el franquismo, Madrid, Centro de Estudios Constitucionales.

García SAn Miguel, L., 1964: «El Derecho natural y la política», Revista de Estudios Políticos, núm. 134, pp. 11-39.

- 1969: Notas para una crítica de la razón jurídica, Madrid, Tecnos.

- 1981: Teoría de la transición. Un análisis del Modelo Español, 1973-1978, Madrid, Editora Nacional.

- 1998: En prensa. Artículos de la transición, Madrid, Tecnos.

GENY, F., 1902: Método de interpretación y fuentes en Derecho privado, Madrid, Hijos de Reus, editores.

Gil Cremades, J. J., 1969: El reformismo español. Krausismo, escuela histórica, neotomismo, Barcelona, Ariel.

- 1983: «Filosofía del Derecho en España (1960-1985)», Anales de la Cátedra Francisco Suárez, núm. 25, pp. 225-243.

— 1987: «Filosofía del Derecho y compromiso político: Alfredo Mendizábal (1897-1981)», Anuario de Filosofía del Derecho, núm. IV, pp. 563-587.

- 1989: «Miguel Sancho Izquierdo (1890-1988)», Anuario de Filosofía del Derecho, núm. VI, pp. 443-452.

- 2002: Derecho y burguesía. Historia de una cátedra zaragozana, Zaragoza, Universidad de Zaragoza.

- 2004: «Estudio Preliminar», en K. ENGISCH, La idea de concreción en el Derecho y en la ciencia jurídica actuales, Granada, Comares.

Gómez Arboleya, E., 1982: Estudios de teoría de la sociedad y del Estado, Madrid, Centro de Estudios Constitucionales.

GonZÁlez Oliveros, W., 1934: «Algunas notas sobre el momento científico de la doctrina racista», Acción Española, núms. 52 y 53, pp. 329-337 y 417-428.

- 1937a: Humanismo frente a comunismo. El primer libro anticomunista publicado en el mundo obra de un pensador español, Valladolid, Imprenta Luis Calderón.

- 1937b: Falange y Requeté, orgánicamente solidarios, Valladolid, Imprenta Católica de Francisco G. Vicente.

GONZÁLEZ ViCÉN, F., 1932: Teoría de la revolución. Sistema e bistoria, Valladolid: Imprenta Allén.

- 1950: «El positivismo en la filosofía del Derecho contemporánea», Revista de Estudios Políticos, núms. 51 y 52 , pp. 31-77 y 13-59.

- 1952: La filosofía del Estado en Kant, Tenerife, Universidad de La Laguna.

- 1969: «La filosofía del Derecho como concepto histórico», Anuario de Filosofía del Derecho, núm. XIV, pp. 15-65.

— 1979: «La obediencia al Derecho», Anuario de Filosofía del Derecho, núm. XXIV, pp. 4-32.

Hernando Serra, M. ${ }^{a}$ P., 2004: «Catedráticos de Derecho en la asamblea nacional consultiva de 1927», en A. MorA (ed.), La enseñanza del Derecho en el siglo XX. Homenaje a Mariano Peset, Madrid, Universidad Carlos III y Dykinson.

IZAGA, L., 1941: «Recensión del libro de Legaz, Luis», Introducción a la teoría del Estado nacional-sindicalista. Razón y Fe, 524-525: 174.

LarenZ, K., 1942: La Filosofía contemporánea del Derecho y del Estado, Madrid, Revista de Derecho Privado. 
Ledesma Ramos, R., 1986: Escritos políticos. La conquista del Estado, 1931, Madrid, edición de Trinidad Ledesma Ramos.

Legaz LaCAmbra, L., 1933a: «Las tendencias dominantes en España en la Filosofía jurídica, política y social», en W. SAUER, Filosofía jurídica y social, Barcelona, Labor.

- 1933b: Estudio crítico de la teoría pura del Derecho y del Estado en la Escuela de Viena, Barcelona, Bosch.

- 1934a: El Estado de Derecho en la actualidad (una aportación a la teoría de la juridicidad), Madrid, Reus.

- 1934b: La filosofía jurídica del nacionalsocialismo, Zaragoza, separata de Universidad.

- 1937: «El humanismo totalitario como tarea de una educación hispánica», Revista de Educación Hispánica, núm. 3, pp. 13-21.

- 1938: «Sentido humanista del nacional-sindicalismo», Jerarquía, núm. 3, pp. 94-112.

- 1942: «Notas sobre el valor actual de la teoría pura del Derecho», Revista General de Legislación y Jurisprudencia, núm. 4, pp. 355-377.

- 1943: Introducción a la ciencia del Derecho, Barcelona, Bosch.

- 1947: Horizontes del pensamiento jurídico (Estudios de filosofía del Derecho), Barcelona, Bosch.

- 1964: «La influencia de Kelsen sobre el pensamiento jurídico español», en S. ENGEL y R. A. Metall (eds.), Law, State and Internacional Legal Order. Essays in honor of H. Kelsen, Knoxwille, The University of Tennesse Press.

- 1971-1972: «Kelsen, hoy», Anuario de Filosofía del Derecho, núm. XVI, pp. 77-93.

- 1976: «La lealtad política», Revista de Estudios Políticos, núm. 210, pp. 5-30.

- 1979: Filosofía del Derecho, Barcelona, Bosch.

Lissarrague Novoa, S., 1944: El poder político y la sociedad, Madrid, Instituto de Estudios Políticos.

- 1948: Introducción a los temas centrales de la Filosofía del Derecho, Barcelona, Bosch.

López Calera, N. M. ${ }^{a}, 1$ 1992: Crónica y utopía. Filosofía de mi tiempo (1973-1991), Granada, Comares.

LÓPEZ-REY, J., 1930: Los estudiantes frente a la dictadura, Madrid, Javier Morata.

MARITAIN, J., 1937: Los rebeldes españoles no hacen una «guerra santa», Madrid-Valencia, Ediciones Españolas.

MEDINA ECHEVARRÍA, J., 1935: La situación presente de la filosofía jurídica. Esquema de una interpretación, Madrid, Revista de Derecho Privado.

MendizÁbal Martín, L., 1928: Tratado de Derecho Natural, Madrid, Imprenta Clásica española.

MendizÁbal Villalba, A., 1933: «Una mitología política (Los principios anticristianos del racismo)», Cruz y Raya, núm. 5, pp. 77-112.

- 1934a: «El comunismo», en VV.AA., La crisis moral, social y económica del mundo (Semana Social de Madrid, 1933), Madrid, Acción Social.

— 1934b: «Neuf journées rouges en Asturie», La Vie Intelectuelle, núm. LVI, pp. 67-73.

- 1937: Aux origines d'une tragédie. La politique espagnole de 1923 à 1936, Paris, Descleé de Brouwer.

- 2009: Pretérito imperfecto. Memorias de un utopista, Oviedo, Real Instituto de Estudios Asturianos.

Mesas de Román, P. J., 2003: «La tesis doctoral de Enrique Gómez Arboleya sobre Hermann Heller: acercamiento del pensamiento filosófico-jurídico del teórico alemán a la España del primer franquismo y adquisición de dos decisivos compañeros de viaje en su trayectoria 
intelectual: el humanismo y la sociología», Anales de la Cátedra Francisco Suárez, núm. 37, pp. 309-336.

MOUNIER, E., 1938: «Letre réponse», Esprit, núm. 68, pp. 243-251.

ORTEGA y GASSET, J., 1980: El hombre y la gente, Madrid, Revista de Occidente y Alianza Editorial.

- 1994: «Un libro sobre la Filosofía del Derecho», en Obras Completas III, Madrid, Alianza Editorial y Revista de Occidente, núms. 25-27.

Ossorio y Gallardo, Á., 1925: «Retorno al absolutismo», Revista General de Legislación y Jurisprudencia, núm. 2, pp. 534-547.

Peces-Barba, G., 1972: Persona, sociedad, Estado. Pensamiento social y político de Maritain, Madrid, Cuadernos para el Diálogo.

- 1973: Derechos fundamentales. I. Teoría General, Madrid, Guadiana.

Pérez Bueno, F., 1925: Actualidad Política. Profecía de la dictadura. Inteligencia e intelectualismo. Patria única (artículos y discursos), 1904-1921, Madrid, Tip. de la Revista de Archivos, Bibliotecas y Museos, 1925.

PÉREz LuÑo, A. E., 1982: «La filosofia e la teoría del diritto in Spagna», Rivista Trimestrale di Diritto e Procedura Civile, núm. XXXVI, pp. 926-945.

- 2007: Trayectorias contemporáneas de la Filosofía y la Teoría del Derecho, Madrid, Tébar.

Primo de Rivera, J. A., 1964: «Informe de José Antonio Primo de Rivera en la defensa de don Galo Ponte, ante el Tribunal de Responsabilidades Políticas de la dictadura», en Textos de doctrina política, Madrid, Sección Femenina.

Puigdollers Oliver, M., 1942: «Prólogo», en G. Del Vecchio, Hechos y doctrinas. Estudios filosóficos, jurídicos y literarios, Madrid, Reus.

Puy Muñoz, F., 1967: Lecciones de Derecho natural, Santiago de Compostela, Porto y Cia.

ReCASÉNS SICHES, L., 1929: Direcciones contemporáneas del pensamiento jurídico (La filosofía del Derecho en el siglo XX), Barcelona, Labor.

- 1931: El poder constituyente. Su teoría aplicada al momento español, Madrid, Javier Morata.

- 1936: Estudios de Filosofía del Derecho, Barcelona, Bosch.

- 1964: «Desenvolvimiento de la filosofía jurídica en España durante los últimos 50 años», Cuadernos para el Diálogo, núm. 8, pp. 12-13.

- 1986: Tratado general de Filosofía del Derecho, 9. ${ }^{a}$ ed., México, Porrúa.

RivaYA, B., 1998a: Filosofía del Derecho y primer franquismo (1937-1945), Madrid, Centro de Estudios Políticos y Constitucionales.

- 1998b: «La reacción contra el fascismo (La recepción en España del pensamiento jurídico nazi)», Revista de Estudios Políticos, núm. 100, pp. 153-177.

- 1998c: «La Filosofía del Derecho como concepto formal (Sobre la filosofía jurídica española de los años sesenta)», Boletín de la Facultad de Derecho de la UNED, núm. 13, pp. 15-48.

- 2000: «Kelsen en España», Revista de Estudios Políticos, núm. 107, pp. 151-177.

- 2001: «La filosofia del diritto in Spagna», Materiali per una Storia della Cultura Giuridica, núm. XXX-1, pp. 263-278.

- 2006: «Sobre el carácter crítico de la Filosofía del Derecho», Revista de Derecho UNED, núm. 1, pp. 275-300.

Rivera Pastor, F., 1918: Lógica de la libertad. Principios de la doctrina del Derecho, Madrid, Francisco Beltrán. 2. ed.

RoCES, W., 1924: «El concepto del Derecho (y su distinción de la moral, de las normas convencionales y del poder arbitrario)», Revista General de Legislación y Jurisprudencia, vol. 144, pp. $408-418$. 
- 1925: «Stammler, filósofo del Derecho y civilista», Revista General de Legislación y Jurisprudencia, vol. 147, pp. 449-468.

Rodríguez Paniagua, J. M. ${ }^{a}$, 1972: La ética de los valores como ética jurídica, Madrid, Universidad Complutense.

Romero Otazo, F., 1930: Sentido democrático de la doctrina política de Santo Tomás, Madrid, Estudios Políticos, Sociales y Económicos.

Rubio Castro, A., 1984: «La filosofía jurídica académica en España (1900-1936)», Revista de la Facultad de Derecho de la Universidad de Granada, núm. 4, pp. 131-144.

Ruiz Giménez, J., 1944: La concepción institucional del Derecho, Madrid, Instituto de Estudios Políticos.

- 1968: El Concilio Vaticano II y los derechos del hombre, Madrid, Cuadernos para el Diá$\log$.

SACRISTÁn, M., 1984: «De la idealidad en el Derecho», en Papeles de filosofía. Panfletos y materiales II, Barcelona, Icaria.

SANCHO IZQUIERDO, M., 1936-1937: «El trabajo y su retribución en una concepción cristiana del mismo», Universidad, núms. 4 y 1, pp. 711-743 y 51-91.

— 1938: «El trabajo y su retribución», Universidad, núm. 3, pp. 357-374.

- 1943: Tratado elemental de Filosofía del Derecho y principios de Derecho natural, Zaragoza, Librería General.

SEMPRÚN GURREA, J. M. ${ }^{a}, 1938$ : «Lettre ouverte a Emmanuel MOUNIER et aux amis d'Esprit», Esprit, núm. 68, pp. 235-243.

SouZA, M. ${ }^{a}$ de L., 2001: El uso alternativo del Derecho. Génesis y evolución en Italia, España y Brasil, Bogotá, Universidad Nacional de Colombia.

STAMmLeR, R., 1929: Economía y Derecho según la concepción materialista de la historia: una investigación filosófico jurídica, Madrid, Reus.

- 1930: Tratado de Filosofía del Derecho, Madrid, Reus.

- 1925-2006: La génesis del Derecho, Madrid, Calpe/Granada, Comares.

Stammler, R., y Rivera Pastor, F., 1922: «Las conferencias del profesor Stammler en la Universidad de Madrid», Revista de Derecho Privado, núm. 104, pp. 129-139; 105: 161-170.

Sturzo, L., 1934: «El Estado totalitario», Cruz y Raya, núm. 28, pp. 7-39.

SueIro, D., y DíAZ-Nosty, B., 1985: Historia del franquismo, Barcelona, Argos Vergara, vol. I. TuÑón DE LARA, M., 1982: Estudios de Historia Contemporánea, Barcelona, Hogar del Libro.

Tusell, J., 1985: El personalismo en España, Madrid, Fundación Humanismo y Democracia.

Tusell, J., y García QueIPO De Llano, G., 1990: Los intelectuales y la República, Madrid, Nerea.

UnAmuno, M. de, 1988: Vida de don Quijote y Sancho, Madrid, Cátedra.

VV.AA., 1966: Crítica del Derecho Natural, Madrid, Taurus. 